\title{
Flexural performance of corroded continuous RC beams rehabilitated by ICCP-SS
}

DOI:

10.1016/j.compstruct.2019.111556

\section{Document Version}

Accepted author manuscript

Link to publication record in Manchester Research Explorer

\section{Citation for published version (APA):}

Su, M., Zeng, C., Li, W., Zhu, J., Lin, W., Ueda, T., \& Xing, F. (2019). Flexural performance of corroded continuous RC beams rehabilitated by ICCP-SS. Composite Structures, 232, 111556.

https://doi.org/10.1016/j.compstruct.2019.111556

\section{Published in:}

Composite Structures

\section{Citing this paper}

Please note that where the full-text provided on Manchester Research Explorer is the Author Accepted Manuscript or Proof version this may differ from the final Published version. If citing, it is advised that you check and use the publisher's definitive version.

\section{General rights}

Copyright and moral rights for the publications made accessible in the Research Explorer are retained by the authors and/or other copyright owners and it is a condition of accessing publications that users recognise and abide by the legal requirements associated with these rights.

\section{Takedown policy}

If you believe that this document breaches copyright please refer to the University of Manchester's Takedown Procedures [http://man.ac.uk/04Y6Bo] or contact uml.scholarlycommunications@manchester.ac.uk providing relevant details, so we can investigate your claim.

\section{OPEN ACCESS}


Su, M.N., Zeng C.Q., Li, W.Q., Zhu, J.H., Lin W.H., Ueda, T., Xing, F., (2020) "Flexural performance of corroded continuous RC beams rehabilitated by ICCP-SS", Composite Structures 22, 111556.

\section{Flexural performance of corroded continuous RC beams}

\section{rehabilitated by ICCP-SS}

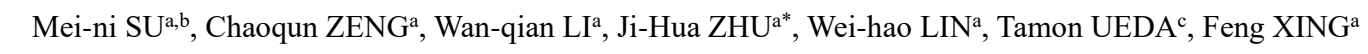

a, Guangdong Province Key Laboratory of Durability for Marine Civil Engineering, School of Civil Engineering, Shenzhen University, Shenzhen, Guangdong 518060, PR China.

b, School of Mechanical, Aerospace and Civil Engineering. University of Manchester, Manchester M1 7JR, UK.

c, Laboratory of Engineering for Maintenance System, Faculty of Engineering, Hokkaido Univ., Sapporo 060-8628, Japan.

${ }^{*}$ Corresponding authors: zhujh@szu.edu.cn

\section{Abstract:}

Continuous beams have the capability to redistribute internal forces due to their indeterminate structural features, leading to enhanced beam deformability, reduced reinforcement congestion and more effective cross-section capacity usage. Thus, continuous reinforced concrete $(\mathrm{RC})$ beams are popular members in most structures. However, RC structures located in corrosive environments might be degraded due to steel reinforcement corrosion. In this study, a recently proposed dual-functional intervention method, impressed current cathodic protection and structural strengthening (ICCP-SS), is adopted to repair degraded beams. The carbon fabric-reinforced cementitious matrix (C-FRCM) composite serves dual functions in the intervention method. The effects of reinforcement corrosion, cathodic protection and the C-FRCM strengthening system on the behaviors of continuous beams should be investigated. The aims of this study are to provide experimental data of continuous RC beams rehabilitated by ICCP-SS technology in corrosive environments and to investigate the structural responses, moment redistributions and design rules of these beams. This paper includes an experimental program, a discussion of the results and a design proposal. The results of electrochemical monitoring showed that the steel reinforcements in continuous beams under corrosive environments are successfully 
protected. Five-point bending test results showed that beams strengthened with C-FRCM composites have higher yielding loads and ultimate loads than corroded beams without protection. By comparing the predicted and measured moment capacities at the central support and midspan, the design methods were found to generally underestimate the moment capacities of the unstrengthened sections and overestimate those of the strengthened sections.

Keywords: Continuous beam; C-FRCM; Corrosion; Impressed Current Cathodic Protection (ICCP); Reinforced Concrete; Structural Strengthening

\section{Introduction}

Continuous reinforced concrete (RC) beams are a common type of statically indeterminate structure. During loading, the stiffness of a beam section changes due to cracking of the concrete section or yielding of the steel. The internal force redistributes with the stiffness changes in the section. Thus, the moment redistribution of a continuous $\mathrm{RC}$ beam is due to the inelastic nature of the beam [1]. Moment redistributions in continuous beams allow more flexibility in structural design by reducing the cross-sectional area or internal reinforcement in the zones with the maximum bending moments [2, 3]. However, the mechanism of a moment redistribution is complex. A moment redistribution occurs upon the formation of plastic hinge regions and is highly dependent on the stiffness or flexural rigidity of the regions outside of the plastic hinge [4]. There have been a great number of studies on the mechanisms and effects of moment redistributions using experimental programs and numerical studies [1-6].

RC structures could deteriorate due to environmental damage. The corrosion of steel reinforcements in concrete structures is one of the major durability concerns, especially in coastal areas and cold regions where deicing salts are heavily used. Corrosion will lead to the loss of cross-sectional area of the reinforcements, cracking of concrete and impair the composite action of steel and concrete [7,8]; as a result, 
the load-bearing capacities and the service lives of corroded RC members will be reduced significantly [9]. Recently, Su et al. [10] and Zhu et al. [11] proposed a dual-functional intervention method to simultaneously provide impressed current cathodic protection (ICCP) and structural strengthening (SS) for degraded RC structures. The ICCP-SS intervention technology has been shown to be able to prevent the further corrosion of steel reinforcements and improve the loading capacities of structures. Previous results show that ICCP-SS is effective for simply supported beams [12] and compressive members [11]. Carbon fabric-reinforced cementitious matrix (C-FRCM) composites are the dual-functional material in the ICCP-SS system, wherein the composites serve as both the anode for cathodic protection and the strengthening material for structural strengthening [13]. When using the ICCP-SS intervention method to rehabilitate continuous RC beams, the FRCM composite is externally bonded to the beams. This new strengthening layer will influence the moment redistribution behaviors of continuous beams.

Currently, almost all studies on strengthened continuous RC beams focus on epoxy-based fiber-reinforced plastic (FRP) strengthening systems. It is well recognized that the ability of a member to redistribute moments is mainly attributed to the member having sufficient ductility for plastic deformation to occur [3]. However, an epoxy-based FRP strengthening layer exhibits elastic deformation until failure and never exhibits yielding, and the presence of an FRP will cause a change in the stiffness of the reinforced beam section, resulting in a different internal force redistribution. The ductility and moment redistribution of an FRP-strengthened continuous beam are different from those of an unstrengthened beam. A few studies were recently conducted on epoxy-based FRP-strengthened continuous RC beams [14-18]. Ashour et al. [14] and El-Refaie et al. [15] found that increasing the carbon fiber-reinforced plastic (CFRP) sheet length cannot prevent premature failure or strengthen the central support and that a beam soffit is the most effective arrangement of the CFRP laminates to enhance the beam loading capacity. Grace et al. [16] proposed using a new fabric to strengthen continuous $\mathrm{RC}$ beam and effectively improve the ductility of the beams compared with those strengthened with carbon 
fiber sheets. Akbarzadeh and Maghsoudi [18] conducted an experimental program to study the flexural behaviors and moment redistributions in reinforced high-strength concrete continuous beams strengthened with CFRP and glass fiber-reinforced plastic (GFRP) sheets. Using a GFRP sheet to strengthen the continuous beam reduced the ductility loss and moment redistribution. However, studies on continuous RC beams strengthened by epoxy-based FRPs are still limited, and investigations on the moment redistribution mechanism of strengthened continuous $\mathrm{RC}$ beams need further investigation.

Recently, FRCM strengthening systems with fiber meshes embedded in cementitious matrices have become increasingly popular for RC structures because, compared to epoxy-based FRP systems, these FRCM strengthening systems have better fire resistances and better corrosion resistances, and they have better compatibilities with concrete substrates and provide greater ductility to the strengthened structures. Although FRCM composites are increasing popular for RC structure interventions, literature on FRCM-strengthened continuous RC beams cannot be found. All the available publications on the FRCM strengthening system are based on simply supported beams. Research has been conducted to investigate the effects of the bonding interface, fabric type (e.g., carbon, glass, and polybenzobisoxazole (PBO)) and fabric layer quantity on the strengthened beams [19-23]. It has been reported that the flexural capacities of simply supported beams could be improved up to $112 \%$ with the strengthening of FRCM composites [24]. Departing from simply supported beams, ductility (i.e., rotation of plastic hinges) is more important for continuous beams, and an FRCM composite has an influence on the ductility of the RC sections. However, the structural responses of continuous beams strengthened by FRCMs still lack experimental data and theoretical studies.

This is the first study on the testing of continuous beams reinforced with FRCM systems. This study aims to generate experimental data on continuous RC beams strengthened with C-FRCM composites under cathodic protection, validate the effectiveness of the new ICCP-SS intervention method for continuous beams, and analyze the ductility and moment redistribution behaviors of continuous beams 
repaired by the ICCP-SS intervention method. This paper first presents an experimental program including nine continuous RC beams in a corrosive environment. The beams were rehabilitated by the ICCP-SS method after accelerated corrosion. Five-point bending tests were conducted on the repaired beams to investigate their behaviors. The effectiveness of the ICCP and C-FRCM strengthening on the behaviors of corroded RC beams are discussed. In addition, the predicted capacities, which are calculated according to existing design rules, are compared with the experimental results to show the appropriateness of the existing design methods for continuous beams rehabilitated by the ICCP-SS intervention method.

\section{Experimental program}

The experimental program was conducted in the Structural Laboratory at Shenzhen University. The duration of the whole experimental program was approximately two years.

\subsection{Test specimens}

A total of nine continuous beams were cast in the experimental program. The labeling system and design of the specimens are presented in Table 1, wherein "CB" indicates a continuous beam, "RF" indicates a reference beam without corrosion, "C" indicates a specimens with accelerated corrosion, "F0" and "F2" indicate 0 and 2 layers of carbon fiber meshes used in the strengthening, respectively, "I0" and "I40" represent $0 \mathrm{~mA} / \mathrm{m}^{2}$ and $40 \mathrm{~mA} / \mathrm{m}^{2}$ current densities, respectively, that are applied to the specimens via ICCP, "T" indicates strengthening on the top surface of the beam for the hogging moment region, and "B" indicates strengthening on the bottom surface of the beam for the sagging moment region. The dimensions and reinforcement arrangement of the beams are shown in Fig. 1. The total length of the beam was 2400 $\mathrm{mm}$, which was composed of $1100 \mathrm{~mm}$ for each span and an extra $100 \mathrm{~mm}$ at both ends for end support. The cross-section was rectangular with a width of $150 \mathrm{~mm}$ and a height of $250 \mathrm{~mm}$. The nominal diameter of the longitudinal reinforcement is $10 \mathrm{~mm}$, while the nominal diameter of the stirrup is $8 \mathrm{~mm}$. All beams, except the reference beam (CB-RF), were cast with sodium chloride (3\% of the cement weight) to 
accelerate the corrosion of the steel reinforcements, as shown in Table 1.

The properties of the materials are summarized in Table 2. The average 28-day compressive strength of the concrete was found to be $52 \mathrm{MPa}$ from concrete cube tests. The tensile strengths of the carbon fiber tows were tested in accordance with ASTM D4018 [25]; a typical stress-strain curve is shown in Fig. 2. The flexural and compressive strengths of the cementitious matrix were obtained by a three-point bending test and a cylinder compressive test in accordance with ASTM C39 [26]. The behavior of the C-FRCM composite plate comprising two layers of carbon fiber meshes was also obtained by tensile coupon tests in accordance with AC434 [27]. All the material properties reported in Table 2 are the average measured values.

\subsection{Pretest preparations}

After 28 days of curing, all continuous beams were placed in an outdoor environment and subjected to accelerated corrosion (see Fig. 3). The accelerated corrosion process consisted of two dry-wet cycles per week and lasted for 12 months. Afterwards, FRCM composites were bonded to the beams. Two beams had FRCM composites bonded to the top surface of the hogging moment region (CB-C-F0-I40-T and CB-C-F2-I40-T), two beams had FRCM composites bonded at the bottom surface of the sagging moment region (CB-C-F0-I40-B and CB-C-F2-I40-B) and three beams had FRCM composites bonded to both surfaces (CB-C-F0-I40-TB, CB-C-F2-I40-TB and CB-C-F2-I40-TB-R); the detailed arrangements are shown in Fig. 4. The C-FRCM composite contains two layers of carbon fiber meshes. The length of the bonded region was approximately $900 \mathrm{~mm}$, and the thickness of the FRCM composite was $10 \mathrm{~mm}$. The FRCM composite plate was designed to cover the entire negative or positive moment zone to prevent peeling failure of the concrete cover. The bonding process is demonstrated in Fig. 5. After the cementitious matrix was cured for 28 days, ICCP was applied to all beams except CB-RF and CB-C-F0-I0 over the whole length by connecting the carbon fiber meshes to the positive pole of a DC power supply and the steel reinforcements to the negative pole, as shown in Fig. 4. The current density adopted in the ICCP process was $40 \mathrm{~mA} / \mathrm{m}^{2}$ for six months. Three specimens were 
designed to be protected only by ICCP (CB-C-F0-I40-T, CB-C-F0-I40-B and CB-C-F0-I40-TB) for comparison purpose; the FRCM composite layers of these members were removed upon the completion of ICCP.

\subsection{Corrosion status measurements}

During the accelerated corrosion and ICCP process, the status of steel reinforcements was monitored by using a CST700 concrete corrosion monitoring meter. Key electrochemical parameters, such as the open-circuit potential, polarization resistance and corrosion current density of the reinforcements in the RC beams, were measured based on the guard ring technology. The built-in algorithm in the equipment can automatically determine the current compensation coefficient according to the concrete resistivity and open-circuit potential. This advanced piece of equipment can also improve the measurement accuracy of the corrosion rate for steel reinforcement in a concrete structure. The reference electrode used in the tester is a saturated copper sulfate solution. All beams were measured at the three plastic hinge regions once each week.

\subsection{Five-point bending tests}

A servo-controlled hydraulic testing machine was used to conduct five-point bending tests, as shown in Fig. 6. An I-shaped steel spreader beam was used. Steel rollers were used at both the loading points and the two end supports; half of a round support was adopted at the midspan support. The test configuration of the beam was symmetric. A load cell was placed at the middle support to determine the loading resistance at each support. Two linear variable differential transducers (LVDTs) were placed under the two loading points to measure the deflections. All specimens were tested to failure under a constant displacement rate of $0.2 \mathrm{~mm} / \mathrm{min}$. The reaction force was recorded by a force sensor connected to the spreader beam during the tests. Strain gauges were attached to carbon fiber meshes, reinforcements and concrete at critical sections.

\subsection{Weight-loss measurements and tensile tests of the reinforcements}


After the bending tests, the reinforcements in the continuous beams were removed to visually inspect their corrosion status and measure their weight loss due to corrosion. The weight-loss measurement was conducted in accordance with ASTM G1-03 [28]: the reinforcements were cut to $100 \mathrm{~mm}$ long, cleaned with a designed solution and then weighed. The cleaning and weighing steps were repeated until the measured value satisfied the requirements of the standard. The weight loss was calculated based on the linear density of the steel by comparing the steel bars before the casting phase and after the bending tests. In addition, tensile tests were conducted on these reinforcements to determine the material properties of the reinforcements after corrosion and ICCP.

\section{Effectiveness of the ICCP process}

\subsection{Open-circuit potentials}

The measured open-circuit potential is plotted in Fig. 7(a). The measured values were compared to the criteria specified in the ASTM standard [29]. During the entire monitoring period, the open-circuit potential of the steel reinforcements in the reference beam CB-RF was always greater than $-200 \mathrm{mv}$, indicating that the steel reinforcements in the specimen had less than a $10 \%$ possibility of being corroded. The open-circuit potential of the reinforcements in the unprotected beam CB-C-F0-I0 was always less than $-350 \mathrm{mv}$, indicating that the reinforcements have a high chance of being corroded. For the beams protected by ICCP, the open-circuit potential was initially situated between $-200 \mathrm{mv}$ and $-350 \mathrm{mv}$, increased slowly upon the application of ICCP, and then stabilized around -200 mv after two months. The results showed that using the C-FRCM as the anode, ICCP was effective for inhibiting steel reinforcement corrosion in a high chloride environment.

\subsection{Corrosion current densities}

The corrosion current densities and corrosion rates of the steel reinforcements in the beams were also measured and compared to the criteria (see Table 3 and Fig. 7) 
corrosion current densities of the reinforcements in the reference beam CB-RF were always less than $0.1 \mu \mathrm{A} / \mathrm{cm}^{2}$, indicating that the reinforcements remained in depassivation. The steel reinforcements in the unprotected beam CB-C-F0-I0 were in a high corrosion rate state, wherein the corrosion current densities were generally greater than $1 \mu \mathrm{A} / \mathrm{cm}^{2}$. For the beams protected by ICCP, the corrosion current densities were approximately $1 \mu \mathrm{A} / \mathrm{cm}^{2}$ at the beginning and decreased to less than $0.1 \mu \mathrm{A} / \mathrm{cm}^{2}$ after three weeks of cathodic protection. Finally, the steel reinforcements were maintained in a passivated state. This finding indicates that for RC structures in substantially corrosive environments, cathodic protection with a $30 \mathrm{~mA} / \mathrm{m}^{2}$ current density is sufficient to inhibit the corrosion of steel reinforcements.

\section{3 Weighing the steel bars}

By visually checking the reinforcements taken from the tested beams (see Fig. 8), it was found that there was almost no rust in the reinforcements from the CB-RF beam or the ICCP-protected beams, while the reinforcement inside the specimen CB-C-F0-I0 without ICCP appeared to be extensively corroded after 18 months. The weighing results in Table 4 showed that the weight loss of the reinforcements in the unprotected specimen CB-C-F0-I0 was the most severe, which was found to be $5.18 \%$.

The reinforcements from the reference beam had almost no mass loss, showing that this specimen was not corroded as expected. The mass loss of the reinforcements from the ICCP-protected beams was approximately 2.06-2.84\%, which is approximately half that of the unprotected beam. The mass losses of the reinforcements from the ICCP-protected beams were believed to be due to corrosion occurring in the accelerated corrosion process. Upon the application of ICCP, the corrosion activities were stopped in these beams; therefore, less weight loss was found in these beams compared to the unprotected beam. The results agree well with the measured open-circuit potentials and corrosion current densities. In addition, the material properties of the reinforcements after accelerated corrosion and ICCP were measured by tensile tests. Fig. 9 shows the relationship between the strength reduction in the reinforcements and the mass loss due to corrosion. Moreover, the reasonable 
agreement between the strength reduction results and the mass loss results illustrated the reliability of the measured data. To summarize, the reference beam was not subjected to corrosion, the unprotected beam was corroded more substantially than the rest of the specimens, and the protected beams were prevented from corrosion upon the application of ICCP. The effectiveness of ICCP using C-FRCM as the anode has been fully demonstrated herein.

\section{Five-point bending test results}

The failure modes of the beams are shown in Figs. 10-11. The full load-deflection responses of all specimens are presented in Fig. 12. The measured ultimate loads $\left(P_{u-\exp }\right)$ and reaction forces at the central support $\left(R_{u \text {-central }}\right)$ and the calculated reaction forces at the end support $\left(R_{u-e n d}\right)$ of all tested beams are shown in Table 5. The loads when the hogging reinforcements yielded and sagging reinforcements yielded are presented in Table 6. Table 7 shows the midspan sagging moments at failure $\left(M_{u s-\exp }\right)$ and the central support hogging moments at failure $\left(M_{u h-e x p}\right)$, which were calculated based on the loads reported in Table 5.

\subsection{Failure modes}

The failure modes of the continuous beams are shown in Figs. 10-11. For all unstrengthened beams (CB-RF, CB-C-F0-I0, CB-C-F0-I40-T, CB-C-F0-I40-B and CB-C-F0-I40-TB), the failure mode was the yielding of the tensile reinforcements followed by concrete crushing. First, the reinforcements yielded at the central support section, then the reinforcements yielded at the midspan section and finally the concrete crushed at the central support section (see Fig. 10(a)). For the beam strengthened at the central support (i.e., the hogging moment region) (CB-C-F2-I40-T), the failure mode was the interfacial separation of the carbon fiber mesh without concrete attached at the central support, as shown in Fig. 10(b). Similarly, the beam strengthened at the midspan (i.e., the sagging moment region) (CB-C-F2-I40-B) failed by the interfacial separation of the carbon fiber mesh followed by concrete crushing at the midspan region (see Fig. 10(c)). For the beams strengthened at both the hogging 
and the sagging regions (CB-C-F2-I40-TB), the failure mode was also carbon fiber mesh separation, as shown in Fig. 10(d). Separation failures of the carbon fiber meshes occurred in all the strengthened beams. Ruptures of the carbon fiber meshes were not observed. The reason for the premature separation of the C-FRCM composite plate might be related to the poor impregnation between the carbon fiber and cementitious matrix. This premature separation should be avoided in future tests by improving the workmanship to increase the efficiency of carbon fiber meshes.

\subsection{Load and moment capacities}

The resistances of the five-point bending beams could be affected by accelerated corrosion, cathodic protection and ICCP-SS. The protection regions (i.e., the hogging or sagging moment region) also influence the loading responses.

\section{Effect of corrosion}

By comparing specimens $\mathrm{CB}-\mathrm{RF}$ and $\mathrm{CB}-\mathrm{C}-\mathrm{F} 0-\mathrm{I} 0$, it can be seen that the loading capacity was substantially reduced when the reinforcements were corroded. The yield loads and the ultimate load of CB-C-F0-I0 were $17.1 \%, 15.2 \%$ and $8.9 \%$ less than those of the reference beam CB-RF (see Table 6). As shown in Table 7, the hogging and sagging moments at the failure of beam CB-C-F0-I0 were $15.2 \%$ and $5.3 \%$ less than those of the reference beam, respectively. This finding is mainly due to the reduction in the effective area of the reinforcements and the deterioration of the bonding interface between the reinforcement and concrete. The accelerated corrosion process seems to be effective, and the capacities of the corroded beams without any protection decreased as expected.

\section{Effect of ICCP}

In comparison with the corroded beam (CB-C-F0-I0), the ultimate loading capacities of the beams protected by ICCP (i.e., specimens CB-C-F0-I40-T, CB-C-F0-I40-B and CB-C-F0-I40-TB) were improved by up to $8.8 \%$ (see Table 6). In addition, the yield loads of the ICCP-protected beams were notably greater than those of the unprotected beams. As shown in Table 7, compared to the unprotected beams (CB-C-F0-I0), the ICCP-protected beams exhibited greater hogging and sagging moments. This finding 
shows that ICCP can effectively prevent the degradation of RC structures in environments with chloride-induced corrosion. However, compared to the reference beam CB-RF, the ultimate loads of the protected beams were generally smaller. This finding indicated that ICCP cannot help recover/improve the loading capacities of degraded structures, although the corrosion of the steel reinforcements can be effectively inhibited; this explains the need for the dual-functional ICCP-SS intervention method.

\section{Effect of ICCP-SS}

The capacities of beams retrofitted by ICCP-SS (i.e., specimens CB-C-F2-I40-T, CB-C-F2-I40-B, CB-C-F2-I40-TB and CB-C-F2-I40-TB-R) were compared to those of the corroded beam (CB-C-F0-I0) and reference beam (CB-RF). The ultimate loading capacities of the ICCP-SS specimens were found to be $13.0 \%$ to $19.2 \%$ greater than that of the corroded beam; similar results were found for the yield loads, as shown in Table 6. Note that for specimen CB-C-F2-I40-B, even though the FRCM composite was bonded at the sagging moment region, the yield load, which is controlled by the yielding of the reinforcements at the hogging moment region, also increased. This phenomenon occurred because the section stiffness was not the same in the longitudinal direction, and the proportion of the internal force distributed on the hogging moment section was less than that in the unstrengthened beams. Through comparisons with the reference beam CB-RF, it was determined that ICCP-SS can successfully recover the loading capacities of degraded beams because all ICCP-SS protected beams exhibited slightly greater ultimate loads than CB-RF. The yielding loads of all beams protected by ICCP-SS were $10.5 \%$ to $52.3 \%$ greater than that of the reference beam. Similar comparisons were conducted on the ultimate moments at the sagging and hogging regions, and the improvement due to C-FRCM strengthening was 2.4-11.0\%, as displayed in Table 7. By comparing the beams retrofitted by ICCP and ICCP-SS, similar conclusions can be drawn: the ICCP-SS technique can improve the capacities of the continuous beams on top of preventing the deterioration of RC beams caused by the corrosion of reinforcements. Thus, the new dual-functional 
ICCP-SS intervention method is superior to the conventional ICCP technology. Effect of protected regions

The ICCP or ICCP-SS technology was applied to the hogging moment region, the sagging moment region or to both regions. From the comparison between the specimens protected by ICCP (i.e., CB-C-F0-I40-T, CB-C-F0-I40-B and CB-C-F0-I40-TB) in Tables 6 and 7, it can be seen that when the reinforcements in the sagging region were protected (CB-C-F0-I40-B), the improvement in the loading capacity was slightly less than that of beam CB-C-F0-I40-T, whose hogging reinforcements were protected. However, from the comparison between the specimens CB-C-F2-I40-T and CB-C-F2-I40-B in Tables 6 and 7, it can be seen that the ultimate load of the beam strengthened in the sagging moment region (CB-C-F2-I40-B) was greater than that of the beam strengthened in the hogging moment region (CB-C-F2-I40-T); this phenomenon occurred because more ductility could be achieved in the hogging moment section without FRCM strengthening, which led to a more sufficient moment redistribution. Moreover, the loading capacities of specimens CB-C-F2-I40-B and CB-C-F2-I40-TB were similar, indicating that FRCM strengthening in the sagging region was rather effective while FRCM strengthening in the hogging region had limited positive effects.

The results of the above analysis indicate that the flexural capacity of a continuous beam could be degraded due to the corrosion of the steel reinforcements. Although the application of ICCP technology can inhibit the corrosion of the reinforcements inside continuous beams, ICCP cannot recover their design capacities. Fortunately, both demands can be satisfied by adopting the dual-functional ICCP-SS intervention method. Tables 5-7 show that using FRCM composites to strengthen continuous beams is an effective technique; the load and moment capacities can be increased by factors of up to 1.19 and 1.29 , respectively. The moment enhancement ratio of a strengthened section in a strengthened beam is more pronounced than the ultimate load enhancement ratio of the same beam, which is different from simply supported beams. 


\subsection{Stiffness and ductility}

By observing the load-deflection curves of all beams (see Fig. 12), it was found that the curves were generally linear before the concrete cracked. The stiffness of the cracked sections decreased so that the stiffness of the beam sections along the longitudinal direction varied. After the steel reinforcements yielded, the load-deflection curves of all beams showed a pronounced turning point entering a plastic region. In comparison, the stiffness of the beam protected by ICCP-SS was larger than those of the other beams. The improvement in the stiffness of the FRCM-strengthened beams became more pronounced after the yielding of the steel rebars. It was also found that the beams with ICCP protection for the rebars on the top had slightly greater stiffness (i.e., CB-C-F0-I40-T and CB-C-F0-I40-TB) than the beams with ICCP protection for the rebars on the bottom (i.e., CB-C-F0-I40-B) and the reference beams.

The ductility of a structure is as important as its strength. To evaluate the structural performance of the strengthened continuous beams, the structural ductility of each continuous beam tested in this study was quantified by using the deflection ductility index proposed by Mukhopadhyaya et al. [32], as shown in Eq. (1); the results are shown in Table 7.

$$
\mu_{\Delta}=\frac{d_{\text {peak }}}{d_{\text {yield }}}
$$

where $d_{\text {peak }}$ is the midspan deflection at peak load and $d_{\text {yield }}$ is the midspan deflection at the yielding of the tensile steel reinforcement.

For the corroded beam without any protection (CB-C-F0-I0), the ductility was 5.33, which is only slightly smaller than that of the reference beam (CB-RF). For the ICCP-protected beams, the ICCP technique seemed unable to improve the ductility, and the measured deflection ductility was not greater than that of the corroded beam (CB-C-F0-I0). Two beams strengthened with C-FRCM composites (CB-C-F2-I40-T, CB-C-F2-I40-TB) exhibited similar ductility compared to the unstrengthened beams, 
while the other two strengthened beams (CB-C-F2-I40-B, CB-C-F2-I40-TB-R) showed only half the ductility of the unstrengthened beams at failure, which was attributed to the premature debonding failure of the C-FRCM plate. The bonding performance between the C-FRCM composite and the concrete beam had a significant effect on the ductility of the beam. It is suggested in the literature that RC sections strengthened by FRPs can be considered mostly brittle with some ductility [33]. However, the FRCM-strengthened RC sections generally have better ductility than epoxy-based FRP-strengthened RC sections due to the slippage between the carbon fibers and cementitious matrix before carbon fiber fracture.

The strains of the tensile reinforcements at the central support $\left(\varepsilon_{\text {steel, } h}\right)$ and the strains of the carbon fiber $(\mathrm{CF})$ meshes at the midspan $\left(\varepsilon_{\text {steel, }}\right)$ when the ultimate loads were reached are presented in Table 8 . Some strain gauges failed before reaching the ultimate loads, and some strain gauges failed before the tests due to the long-term cathodic protection. Therefore, for these specimens, it is indicated in Table 8 that the strains were larger than the last measured value. The majority of steel reinforcements yielded at failure, except for one beam repaired with ICCP-SS (CB-C-F2-I40-TB-R). It is not possible to determine the changes in ductility due to the application of the ICCP technique because the reinforcements in both the corroded beam without any protection and the beams protected only by ICCP yielded and failed before reaching the ultimate load. For the beams protected with ICCP-SS, beam CB-C-F2-I40-TB-R exhibited a lower ultimate tensile strain in the reinforcements compared to the other beams. Based on the limited results, it seems that FRCM strengthening reduced the rotational capacities of the RC sections.

In summary, regarding the stiffness, ICCP had minimal effects, while the ICCP-SS technique enhanced the stiffness of the beam due to the strengthening by the FRCM composite plates. Regarding the ductility of the beam, the effects of the ICCP technique were negligible, but the ICCP-SS technique decreased the ductility.

\subsection{Effective strain of the C-FRCM composite}


During the loading process, the strains of the CF meshes embedded in the C-FRCM composite were measured by strain gauges. Table 9 shows the strains of the CF

449 meshes at the central support $\left(\varepsilon_{f r p, h}\right)$ and the strains of the CF meshes at the midspan

450

451

452

453

454

455

456

457

458

459

460

461

462

463

464

465

466

467

468

469

470

471

472

473

474

475

$\left(\varepsilon_{f r p, s}\right)$ when the ultimate loads were reached. The strains of the CF meshes at ultimate loads were found to be approximately $0.00194-0.00320$, which are smaller than the effective design strain specified in ACI 549.4R [34] (0.0085), ACI 440.2R-08 [35] (0.0116) and Ashour et al. [14] (0.0156). This lower strain is because debonding failure was observed at the interface of the CF mesh and cementitious matrix during the experiment. The occurrence of immature interfacial failure resulted in the low utilization of the CFs. Thus, the existing design methods overestimated the capacities of the strengthened sections, which is further discussed in the following section.

\section{Result comparisons with the design methods}

In this section, existing design methods for RC continuous beams are described. The load capacity prediction of continuous beams comprised two parts: the prediction of the cross-section flexural capacity and the prediction of the global flexural behavior. The experimental results were compared to the predicted ultimate loads. All material properties and geometric information were obtained from tests and measurements. All safety factors were set to unity. The results are shown in Tables 10-12.

\subsection{Cross-section flexural capacity prediction}

In this study, there were two types of cross-sections (i.e., strengthened and unstrengthened) at two different critical locations (i.e., central support and midspan). The flexural capacities of the strengthened and unstrengthened sections were calculated in accordance with ACI 549.4R Guide to Design and Construction of Externally Bonded Fabric-Reinforced Cementitious Matrix (FRCM) Systems for Repair and Strengthening Concrete and Masonry Structures [34], ACI 440.2R Guide for the Design and Construction of Externally Bonded FRP Systems for Strengthening [35] and Ashour et al. [14]. A brief explanation of these design methods is presented below, while the 
476 detailed calculation procedures can be found in Su et al. [12] and Ashour et al. [14].

477 The calculated moment capacities for the critical sections in the hogging and sagging

478 regions in all the beams are presented in Table 10 , where $M_{u h-549}$ and $M_{u s-549}$ are the

479 hogging and sagging moment capacities predicted by the guidelines in ACI 549.4R

480 [34], $M_{u h-440}$ and $M_{u s-440}$ are the hogging and sagging moment capacities predicted by

481 the guidelines in ACI 440.2R-08 [35], and $M_{u h-A s h}$ and $M_{u s-A s h}$ are the predicted

482 hogging and sagging moment capacities according to Ashour et al. [14].

483 The ACI 549 approach

484 The flexural capacity prediction is detailed in Chapter 11 of ACI 549.4R [34], which 485 was developed specifically for FRCM-strengthened cross-sections. The design 486 bending moment capacity $\left(M_{n}\right)$ is the combination of the flexural strength provided by 487 the steel reinforcements $\left(M_{n s}\right)$ and the externally bonded FRCM $\left(M_{n f}\right)$, as given in Eq. 488 (2).

$$
M_{n}=M_{n s}+M_{n f}
$$

490 The depth of the neutral axis was determined iteratively calculating until the 491 equilibrium of the internal forces was satisfied. The failure criteria were determined 492 by comparing the concrete crushing strain and the effective tensile strain of the 493 FRCM composite. The effective strain of the FRCM at failure was set equal to the 494 lesser of the design strain and the value of 0.012, while the design strain of the FRCM 495 composite was defined as the average value minus one standard deviation based on 496 the test results. Once the failure mode of the cross-section was determined, either 497 concrete crushing or FRCM failure (rupture or debonding), the strains and stresses in 498 other materials could be calculated.

499 The ACI 440 approach

500 The flexural capacity prediction in ACI 440.2R-08 [35] is codified in Chapter 10, 501 which was developed for epoxy-based FRP-strengthened cross-sections. The design 502 procedure specified in ACI 440.2R-08 [35] is similar to that in ACI 549.4R [34]. Note 503 that the debonding strain of the FRP $\left(\varepsilon_{f d}\right)$ is given by Eq. (3). It is assumed that FRP 504 debonding will occur before the FRP ruptures. Similarly, the failure mode of the 
section could be determined by comparing this FRP debonding strain given by Eq. (3) and the effective design strain of FRP $\left(\varepsilon_{f e}\right)$ for concrete crushing (i.e., $\varepsilon_{c u}$ is taken as 0.003 ) given by Eq. (4).

$$
\begin{aligned}
\varepsilon_{f d} & =0.41 \sqrt{\frac{f_{c}^{\prime}}{n E_{f} t_{f}}}<\varepsilon_{f u} \\
\varepsilon_{f e} & =\varepsilon_{c u}\left(\frac{h_{f}-c_{u}}{c_{u}}\right)
\end{aligned}
$$

\section{The Ashour's approach}

Ashour et al. [14] presented a method for estimating the flexural capacity of an FRP-strengthened section. The design methodology was developed based on the assumption that a perfect bond exists between CFRP laminates and the concrete surface, and the stress-strain behavior of the CFRP laminate is linear until rupture. The failure modes considered by Ashour et al. [14] were concrete crushing (i.e., the concrete strain at the extreme fiber compression reaches the ultimate strain) and CFRP rupture (i.e., the CFRP laminates strain at the extreme fiber tension reaches the ultimate strain). The calculation of flexural capacity comprised two steps: (1) calculate the area of the CFRP laminates that distinguishes between concrete crushing and tensile rupture of the CFRP laminates, and (2) calculate the flexural capacity based on the determined failure mode by comparing the actual CFRP area with the critical area obtained from step (1). In step (2), similarly, the neutral axis depth was initially assumed, and the correct value was iteratively determined when the equilibrium of internal forces was satisfied.

\subsection{Global flexural mechanism}

A continuous beam is a type of indeterminate structure, allowing for possible redistributions of bending moments from zones that are stressed plastically to zones that are not yet plastic. Moment redistribution will occur only in members with sufficient ductility. For members without sufficient ductility, the global elastic design 
approach should be taken, which specifies the failure criteria as the occurrence of the first plastic hinge, i.e., the first critical section reaches its flexural capacity. For members with sufficient ductility, the plastic global design approach is taken (i.e., the failure of the member occurs when all critical sections reach their flexural capacities), and a collapse mechanism of the member is formed. However, the required ductility level of an indeterminate structure for moment redistribution is still unclear. It is known that FRP strengthening reduces the ductility of an RC structure, but the precise reduction in the ductility of an RC member after FRP strengthening and any possible moment redistribution for strengthened beams is still open for discussion [35]. Therefore, both the global elastic and the plastic approaches are considered in this study. All the calculations are based on the cross-section capacities obtained from Section 5.1 (see Table 10).

\section{$\underline{\text { The global elastic approach }}$}

For the considered five-point bending beam, the bending moment diagram is shown in Fig. 13(a) within the elastic range across the entire beam. According to elastic theory, the ratio between the maximum hogging moment and sagging moment was 1.2 for the loading configuration considered in this study. As the applied load increased, the cross-section at the central support first reached its flexural capacity (except beam CB-C-F2-I40-T), and the beam was deemed as a failure; no redistribution of the bending moments occurred in this case. According to Fig. 13(a), the ultimate load capacity following the global elastic approach $\left(P_{u}^{e l}\right)$ is given by Eq. (5). Table 12 presents the predicted load capacities of all tested beams by using the global elastic approach and the comparison with experimental results.

$$
P_{u}^{e l}=\min \left(\frac{32}{3} \frac{M_{u h}}{l}, \frac{64}{5} \frac{M_{u s}}{l}\right)
$$

\section{The global plastic approach}

The global plastic design approach for continuous beams considers the occurrence of moment redistribution beyond the point when the first critical section reached its 
flexural capacity. According to the plastic theory, failure of a continuous beam occurs when the cross-sections at the midspan and central support all reach their flexural capacities, as shown in Fig. 13(b). Accordingly, the ultimate load $\left(P_{u}^{p l}\right)$ of the five-point bending beam can be calculated based on the force equilibrium, as shown in Eq. (6). Note that the global plastic mechanism presented above is suitable only for ductile members with sufficient rotation capacities. This stipulation is considered herein for the FRCM-strengthened beams to examine the available ductility of the FRCM-strengthened beams. Table 12 presents the predicted load capacities of all tested beams by using the plastic global approach and the comparison with experimental results.

$$
P_{u}^{p l}=\frac{4}{l}\left(M_{u h}+M_{u s}\right)
$$

\subsection{Result comparisons}

Table 11 presents the comparison of the measured bending moments at the critical sections and the predictions by the guidelines in ACI549.4R-2013 [34], the guidelines in ACI440.2R-08 [35] and the approach in Ashour et al. [14]. For all unstrengthened sections, the predictions from the three considered design methods are the same, which all underestimated the moment capacities of the full cross-sections. The conservative estimations provided by the existing design methods have also been reported in other studies [12]. Among all the unstrengthened sections, the prediction was closest to the bending moment in the sagging region of the reference beam (CB-RF). For all unstrengthened sections, the prediction accuracies were generally similar regardless of whether the section was protected by ICCP. This finding is because the measured cross-sections of the steel reinforcements were used in the predictions. For the strengthened sections, the predictions made by the guidelines in ACI549 were found to be the closest to the measured bending moments among the design methods. The bending moment at the central support section was found to reach $87-90 \%$ of its flexural design capacities, while the bending moment at the midspan section was approximately $75-79 \%$ of its design capacities. In summary, although brittle peeling failure of the FRCM composite was the failure mode in some 
589 of the tested strengthened beams, most beams were close to achieving their flexural 590 capacity predicted by ACI549. The reason for the better performance of ACI549 for

591 FRCM-strengthened sections is that ACI549 employs the effective tensile strain of

592 C-FRCM composites in the prediction instead of the material properties of CFRP. The 593 material properties of the C-FRCM composites could be determined by tensile coupon 594 tests. Both the failure mode and the loading responses of the FRCM composite are 595 different from those of the CFRP sheet/meshes or epoxy-based CFRPs [27, 33].

596 The total load capacities of the continuous beams obtained from the experiments 597 and theoretical analyses are shown in Table 12. For the unstrengthened beams, all 598 predicted load capacities were found to be conservative compared to the testing 599 600 plastic approach yielded more accurate predictions than the global elastic approach 601 for all beams. The accuracy level of the global plastic approach for all unstrengthened 602 beams was similar, which was approximately 1.11 to 1.19 for the 603 experimental-to-predicted ratios. The results indicated that similar moment redistributions occurred in all the unstrengthened beams. The effects of ICCP on the moment redistribution were minimal. For strengthened beams, the majority of predictions using the globally plastic design approach overestimated the capacities of FRCM-strengthened beams except for CB-C-F2-I40-T. Compared to the global plastic approach, the global elastic approach was found to be more appropriate for FRCM-strengthened beams based on the same cross-section capacities presented in Table 10. This finding also indicated that little moment redistribution occurred in the strengthened beams. In particular, the global plastic approach provided the most accurate predictions for beams repaired with ICCP-SS when ACI549 was adopted.

Although FRCM strengthening could increase the flexural capacity of the RC section, this strengthening method decreased the ductility of the cross-section, which meant that less moment redistribution could occur. Based on the above discussion and the results in Tables 11-12, among the design methods, ACI549 seems to be able to provide more accurate predictions for bending moments of FRCM-strengthened sections due to the adoption of the material model of FRCM composite; the moment 
redistribution is limited in strengthened beams, which failed upon the occurrence of the first plastic hinge, so the global elastic approach is more appropriate. In conclusion, for beams repaired with ICCP-SS, it is recommended to use the guidelines in ACI549 [34] to calculate the cross-section capacity together with the global elastic approach for the beam analysis.

\section{Conclusions}

To date, the majority of in situ RC beams are continuously constructed. To solve the durability problems of RC continuous beams caused by reinforcement deterioration from environments with chloride-induced corrosion, a dual-functional intervention method was applied to RC continuous beams. This recently proposed method provided cathodic protection and structural strengthening to the existing beams using FRCM system. This paper presented an experimental program of nine RC continuous beams protected by different current densities and strengthened with different arrangements of C-FRCM composites. The chloride-containing RC beams were placed in an open air space for 360-day accelerated corrosion and 180-day cathodic protection. Electrochemical signals such as the open-circuit potential, corrosion current densities and mass loss of the steel reinforcement were measured to show the effectiveness of ICCP. Afterwards, the beams were evaluated with five-point bending tests. During the bending tests, the strains of the steel reinforcement and the $\mathrm{CF}$ meshes were measured. The ICCP-SS intervention method improved the capacities of the continuous beams subjected to corrosion; however, this method also reduced the ductility of the beams. The strengthening effect of the C-FRCM was more pronounced when bonded at the sagging region. The comparison of the design codes found that the global elastic design approach was more accurate than the plastic approach for FRCM-strengthened beams. Therefore, it is recommended to predict the capacity of FRCM-strengthened beams by using the design rules in ACI549 to calculate the cross-section capacity together with the global elastic approach for the beam analysis. 


\section{Acknowledgements}

651 We would like to thank the support from the Chinese National Natural Science 652 Foundation (51778370, 51538007), Natural Science Foundation of Guangdong 653 (2017B030311004), the Shenzhen science and technology project 654 (JCYJ20170818094820689). Meini Su and Chaoqun Zeng contributed equally to the 655 paper.

656

\section{Notation list}

$658 \quad c_{u} \quad$ neutral axis depth at steel yielding state

$659 \quad d_{\text {peak }} \quad$ mid-span deflection at peak load

$660 d_{\text {yield }} \quad$ mid-span deflection at the yielding of tension steel reinforcement

$661 \quad E_{f} \quad$ Elastic modulus of FRP

$662 f_{c}^{\prime} \quad$ compressive strength of concrete in cylinder,

$663 h_{f} \quad$ distance from extreme compression fibre to centroid of carbon fibre

664 tension reinforcement;

$665 \quad M_{n} \quad$ design bending moment capacity

$666 \quad M_{n f} \quad$ flexural strength provided by externally bonded FRCM

$667 \quad M_{n s} \quad$ flexural strength provided by the steel reinforcements

$668 \quad M_{u h} \quad$ hogging moment capacities

$669 M_{u h-440} \quad$ hogging moment capacities predicted by the ACI $440.2 \mathrm{R}-08[35]$

$670 \quad M_{u h-549} \quad$ hogging moment capacities predicted by the ACI 549.4R[34]

$671 \quad M_{u h-A s h} \quad$ hogging moment capacities predicted by [14]

$672 \quad M_{\text {uh-exp }} \quad$ central-support hogging moments at ultimate

$673 \quad M_{u s} \quad$ sagging moment capacities

$674 M_{u s-440} \quad$ sagging moment capacities predicted by the ACI 440.2R-08 [35]

$675 M_{u s-549} \quad$ sagging moment capacities predicted by the ACI 549.4R [34]

$676 \quad M_{u s-A s h} \quad$ sagging moment capacities predicted by [14] 
$677 \quad M_{u s-\exp } \quad$ mid-span sagging moments at ultimate

$678 \quad n \quad$ Number of layers of carbon fibre meshes

$679 \quad P_{u-\exp } \quad$ experimental ultimate loads

$680 \quad P_{u}^{e l} \quad$ ultimate load predicted by the global elastic approach

$681 \quad P_{549}^{e l} \quad$ ultimate load predicted by the global elastic approach and the ACI

$682 \quad 549.4 \mathrm{R}[34]$

$683 P_{440}^{e l} \quad$ ultimate load predicted by the global elastic approach and the ACI

$684 \quad 440.2 \mathrm{R}-08[35]$

$685 P_{A s h}^{e l} \quad$ ultimate load predicted by the global elastic approach and Ashour et al.

$686 \quad[14]$

$687 \quad P_{u}^{p l} \quad$ ultimate load predicted by the global plastic approach

$688 \quad P_{549}^{p l} \quad$ ultimate load predicted by the global plastic approach and the ACI

$689 \quad 549.4 \mathrm{R}[34]$

$690 \quad P_{440}^{p l} \quad$ ultimate load predicted by the global plastic approach and the ACI

$691 \quad 440.2 \mathrm{R}-08[35]$

$692 \quad P_{A s h}^{p l} \quad$ ultimate load predicted by the global elastic approach and Ashour et al.

$693 \quad[14]$

$694 \quad R_{u \text {-central }}$ reaction forces at the central support

$695 \quad R_{u-e n d} \quad$ calculated reaction forces at the end-support

$696 \quad t_{f} \quad$ thickness of carbon fibre meshes

$697 \quad \mu_{\Delta} \quad$ deflection ductility

$698 \quad \varepsilon_{c u} \quad$ concrete crushing strain

$699 \quad \varepsilon_{f d} \quad$ debonding strain of FRP

$700 \quad \varepsilon_{f e} \quad$ effective design strain of FRP

$701 \varepsilon_{f r p, h} \quad$ strains of CF meshes at the central support 


$\begin{array}{lll}702 & \varepsilon_{f r p, s} & \text { strains of CF meshes at the mid-span } \\ 703 & \varepsilon_{f u} & \text { ultimate strain of FRP } \\ 704 & \varepsilon_{\text {steel }, h} & \text { strains of tensile reinforcements at the central support } \\ 705 & \varepsilon_{\text {steel,s }} & \text { strains of tensile reinforcements at the mid-span }\end{array}$

\section{References:}

[1] Visintin, M. S. Mohamad Ali, T. Xie, A.B. Sturm, Experimental investigation of moment redistribution in ultra-high performance fibre reinforced concrete beams. Construction and Building Materials, 166 (2018) 433-444

[2] Mattock A. H., Redistribution of design bending moments in reinforced concrete continuous beams. Proceedings of the Institution of Civil Engineers. (1959) 13(1): 3546.

[3] Ilker Fatih Kara, Ashraf F. Ashour, Moment redistribution in continuous FRP reinforced concrete beams. Construction and Building Materials, 49 (2013) 939-948

[4] Visintin,P., Oehlers, J., Mechanics-based closed-form solutions for moment redistribution in RC beams, Struct. Concr. 17 (3) (2016) 377-389.

[5] Scott R. H., Whittle R. T. Moment redistribution effects in beams. Mag. Concr. Res. (2005) 57(1):9-20.

[6] Oehlers D. J., Haskett M., Mohamed Ali MS., Griffith M. C. Moment redistribution in reinforced concrete beams. Proc. Inst. Civ. Eng. - Struct. Build. (2010) 163(SB3):16576.

[7] Zhang, D., Zhao, Y., Jin, W., Ueda, T. and NaKai, H. (2017). Shear strengthening of corroded reinforced concrete columns using pet fiber based composites. Engineering Structures. 153, 757-765.

[8] Li, D.W., Xiong, C., Huang, T., Wei, R., Han, N.X., Xing, F. A simplified constitutive model for corroded steel bars. Construction and Building Materials, 186 (2018) 11-19.

[9] Zhou, H.J., Lu, J.L., Xu, X., Dong, B. Q, Xing, F., Effects of stirrup corrosion on bond-slip performance of reinforcing steel in concrete: An experimental study. CONSTRUCTION AND BUILDING MATERIALS. 2015. 93, 257-266.

[10] Su, M., Wei, L, Zhu, J.H., Ueda T., Guo G. and Xing, F. "Experimental investigation of the ICCP-SS technique based on the C-FRCM composite", Journal of Composites for Construction, ASCE, in press.

[11] Zhu J. H., Su M. N., Huang J. Y., T Ueda, F Xing. The ICCP-SS technique for retrofitting reinforced concrete compressive members subjected to corrosion. Construction and Building Materials, (2018) 167:669-679.

[12] Su M. N., Wei L. L., Zeng Z. W., Ueda T., Xing F., Zhu J. H. A solution for sea-sand reinforced concrete beams, Construction and Building Materials, 2019, in press.

[13] Zhu, J. H., Wei, L., Moahmoud, H., Redaelli, E., Xing, F. *, Bertolini, L. (2017). "Investigation on CFRP as dual-functional material in chloride-contaminated solutions." 
Construction and Building Materials, 151, 127-137.

[14] Ashour A. F., El-Refaie S. A., Garrity S. W. Flexural strengthening of RC continuous beams using CFRP laminates. Cem. Concr. Compos. (2004) 26:765-75.

[15] El-Refaie S. A., Ashour A. F., Garrity S. W. Sagging and hogging strengthening of continuous reinforced concrete beams using carbon fiber-reinforced polymer sheets. ACI Struct J (2003) 100(4):446-53.

[16] Grace N. F., Ragheb W. F., Abdel-Sayed G. Strengthening of cantilever and continuous beams using new triaxially braided ductile fabric. ACI Struct. J. (2004) 101(2):237-44.

[17] Liu I. S. T., Oehlers D. J., Seracino R. Moment redistribution in FRP and steel-plated reinforced concrete beams. J Compos Construct, ASCE (2006) 10(2):115-24.

[18] Akbarzadeh H., Maghsoudi A. A . Experimental and analytical investigation of reinforced high strength concrete continuous beams strengthened with fiber reinforced polymer. Materials \& Design, (2010) 31:1130-1147.

[19] Banholzer, B.; Brockmann, T.; Brameshuber, B. Material and bonding characteristics for dimensioning and modelling of textile reinforced concrete (TRC) elements. Mater. Struct. (2006) 39 (8): 749-763.

[20] Brückner, A.; Ortlepp, R.; Curbach, M. "Textile reinforced concrete for strengthening in bending and shear." Mater. Struct. (2006) 39 (8): 741-748.

[21] Al-Salloum, Y. A., Elsanadedy, H. M., Alsayed, S. H. and Iqbal., R. A. Experimental and numerical study for the shear strengthening of reinforced concrete beams using textile-reinforced mortar. J. Compos. Constr. (2012) 16 (1): 74-90.

[22] Hashemi, S., and Al-Mahaidi, R., Experimental and finite element analysis of flexural behavior of FRP-strengthened RC beams using cement-based adhesives. Construction and Building Materials (2012) 26 (1): 268-273.

[23] Wang, W.W., Dai, J. G. and Harries, K. A. Performance evaluation of RC beams strengthened with an externally bonded FRP system under simulated vehicle loads. J. Bridge Eng. (2013) 18 (1): 76-82

[24] Loreto, G., Leardini, L., Arboleda, D. and Nanni, A. Performance of RC slab-type elements strengthened with fabric-reinforced cementitious matrix composites. J. Compos. Constr. (2014) 18 (3): A4013003.

[25] ASTM D4018. Standard test methods for properties of continuous filament carbon and graphite fiber tows. ASTM, 100 Barr Harbor Drive, West Conshohocken, PA 19428-2959, United States (2017).

[26] ASTM C348-14. Standard test method for flexural strength of hydraulic-cement mortars. ASTM, 100 Barr Harbor Drive, West Conshohocken, PA 19428-2959, United States (2007).

[27] AC434. Acceptance criteria for masonry and concrete strengthening using fabric-reinforced cementitious matrix (FRCM) and steel reinforced grout (SRG) composite systems. International Code Council (2016).

[28] ASTM G1-03. Standard practice for preparing, cleaning, and evaluating corrosion test specimens. ASTM, 100 Barr Harbor Drive, West Conshohocken, PA 19428-2959, United States (2017).

[29] ASTM C876. Standard test method for corrosion potential of uncoated reinforcing steel in concrete. West Conshohocken, PA 19428-2959, United States, (2009). 
[30] ASTM G102-89. Standard practice for calculation of corrosion rates and related information from electrochemical measurements. West Conshohocken, PA 19428-2959, United States, (2015).

[31] Grantham, M-G., Herts, B., Broomfield, J. The use of linear polarisation corrosion rate measurements in aiding rehabilitation options for the deck slabs of a reinforced concrete underground car park, Construction and Building Materials (1997) 11, 215-224.

[32] Mukhopadhyaya, P., Swamy, N. and Lynsdale, C. Optimizing structural response of beams strengthened with GFRP plates. Journal of Composites for Construction, ASCE. (1998) 2(2):87-95.

[33] Oehlers, D. J., and Seracino. R., Design of FRP and steel plated RC structures: retrofitting beams and slabs for strength, stiffness and ductility, (2004) Elsevier.

[34] ACI549R-13. Guide to design and construction of externally bonded Fabric-Reinforced Cementitious Matrix (FRCM) systems for repair and strengthening concrete and masonry Structures. (2013). American Concrete Institute.

[35] ACI 440.2R-08. Guide for the Design and Construction of Externally Bonded FRP Systems for Strengthening Concrete Structures. (2008). American Concrete Institute. 
Table 1. Details of the test specimens

\begin{tabular}{|c|c|c|c|c|c|}
\hline \multirow{2}{*}{ Specimens } & \multirow{2}{*}{$\begin{array}{l}\text { Accelerated } \\
\text { corrosion }\end{array}$} & \multicolumn{2}{|c|}{$\begin{array}{c}\text { Strengthened by CFRP } \\
\text { (layers) }\end{array}$} & \multicolumn{2}{|c|}{$\mathrm{ICCP}$} \\
\hline & & $\begin{array}{l}\text { Hogging } \\
\text { region }\end{array}$ & $\begin{array}{l}\text { Sagging } \\
\text { region }\end{array}$ & $\begin{array}{l}\text { Hogging } \\
\text { region }\end{array}$ & $\begin{array}{c}\text { Sagging } \\
\text { region }\end{array}$ \\
\hline CB-RF & $\mathrm{N}$ & 0 & 0 & $\mathrm{~N}$ & $\mathrm{~N}$ \\
\hline CB-C-F0-I0 & $\mathrm{Y}$ & 0 & 0 & $\mathrm{~N}$ & $\mathrm{~N}$ \\
\hline CB-C-F0-I40-T & Y & 0 & 0 & $\mathrm{Y}$ & $\mathrm{N}$ \\
\hline CB-C-F0-I40-B & $\mathrm{Y}$ & 0 & 0 & $\mathrm{~N}$ & $\mathrm{Y}$ \\
\hline CB-C-F0-I40-TB & $\mathrm{Y}$ & 2 & 2 & $\mathrm{Y}$ & $\mathrm{Y}$ \\
\hline CB-C-F2-I40-T & $\mathrm{Y}$ & 2 & 0 & Y & $\mathrm{N}$ \\
\hline CB-C-F2-I40-B & $\mathrm{Y}$ & 0 & 2 & $\mathrm{~N}$ & Y \\
\hline CB-C-F2-I40-TB & $\mathrm{Y}$ & 2 & 2 & Y & Y \\
\hline CB-C-F2-I40-TB-R & $\mathrm{Y}$ & 2 & 2 & $\mathrm{Y}$ & $\mathrm{Y}$ \\
\hline
\end{tabular}

833

834

835

836

837

838

Table 2. Material properties of the main components

839

\begin{tabular}{|c|c|c|c|c|c|}
\hline Materials & & \multicolumn{2}{|c|}{ Strength (MPa) } & \multirow{2}{*}{$\begin{array}{c}\text { Elastic } \\
\text { modulus } \\
(\mathrm{GPa}) \\
---\end{array}$} & \multirow{2}{*}{$\begin{array}{l}\text { Ultimate } \\
\text { strain } \\
(\%) \\
---\end{array}$} \\
\hline Concrete & & Compressive & 52 & & \\
\hline \multirow{2}{*}{$\begin{array}{l}\text { Steel } \\
\text { reinforcements }\end{array}$} & $\mathrm{C} 8$ & $\begin{array}{l}\text { Yielding tensile } \\
\text { Ultimate tensile }\end{array}$ & $\begin{array}{l}412 \\
572 \\
\end{array}$ & 200 & --- \\
\hline & $\mathrm{C} 10$ & $\begin{array}{l}\text { Yielding tensile } \\
\text { Ultimate tensile }\end{array}$ & $\begin{array}{l}480 \\
602 \\
\end{array}$ & 200 & --- \\
\hline CFRP & & Tensile & 3519 & 223 & 1.58 \\
\hline \multicolumn{2}{|l|}{$\begin{array}{l}\text { Cementitious } \\
\text { matrix }\end{array}$} & $\begin{array}{c}\text { Flexural } \\
\text { Compressive }\end{array}$ & $\begin{array}{l}10.4 \\
80.2 \\
\end{array}$ & --- & --- \\
\hline C-FRCM comp & osite & Tensile & 1126 & 81 & 0.85 \\
\hline
\end{tabular}


Table 3. Corrosion rates of the reinforcements in concrete calculated in accordance with ASTM G102-89 [30]

\begin{tabular}{ccc}
\hline Corrosion current density & Corrosion rate & Corrosion condition \\
\cline { 1 - 2 }$\mu \mathrm{A} / \mathrm{cm}^{2}$ & $\mu \mathrm{m} / \mathrm{y}$ & Negligible \\
$<0.1$ & $<1.1$ & Low corrosive \\
$0.1 \sim 0.5$ & $1.1 \sim 5.5$ & Moderate corrosive \\
$0.5 \sim 1$ & $5.5 \sim 11$ & Highly corrosive \\
$>1$ & $>11$ &
\end{tabular}

851

852

853

854

855

856

857

858

859

Table 4. Weight measurement of the reinforcements after five-point bending tests

860

\begin{tabular}{llcc}
\hline Specimens & & $\begin{array}{c}\text { Linear density } \\
(\mathrm{g} / \mathrm{mm})\end{array}$ & $\begin{array}{c}\text { Weight } \\
\text { loss }\end{array}$ \\
\hline Reference weight* & & 0.6019 & --- \\
\hline CB-RF & & 0.6015 & $0.07 \%$ \\
\hline CB-C-F0-I0 & & 0.5707 & $5.18 \%$ \\
\hline \multirow{2}{*}{ CB-C-F0-I40-T } & Protected & 0.5848 & $2.84 \%$ \\
\cline { 2 - 4 } CB-C-F0-I40-B & Unprotected & 0.5748 & $4.50 \%$ \\
\cline { 2 - 4 } & Protected & 0.5769 & $4.15 \%$ \\
\hline CB-C-F0-I40-TB & & 0.5860 & $2.64 \%$ \\
\hline \multirow{2}{*}{ CB-C-F2-I40-T } & Protected & 0.5870 & $2.48 \%$ \\
\cline { 2 - 4 } CB-C-F2-I40-B & Unprotected & 0.5851 & $2.79 \%$ \\
\cline { 2 - 4 } CBnprotected & 0.5772 & $4.10 \%$ \\
\hline CB-C-F2-I40-TB & Protected & 0.5866 & $3.95 \%$ \\
\hline CB-C-F2-I40-TB-R & & 0.5873 & $2.54 \%$ \\
\hline
\end{tabular}


862

863

864

865

866

867

868

869

870

871

872

873

874

875

876

877

878

879

880

881

882

*Note: the reference weight was obtained by measuring the steel bars before the casting phase of specimens

Table 5. Results of the five-point bending tests

\begin{tabular}{lccc}
\hline Specimens & $\begin{array}{c}P_{u \text {-exp }} \\
(\mathrm{kN})\end{array}$ & $\begin{array}{c}R_{u \text {-central }} \\
(\mathrm{kN})\end{array}$ & $\begin{array}{c}R_{u \text {-end }} \\
(\mathrm{kN})\end{array}$ \\
\hline CB-RF & 240.6 & 164.8 & 37.9 \\
CB-C-F0-I0 & 219.1 & 147.3 & 35.9 \\
CB-C-F0-I40-T & 233.2 & 157.2 & 38.0 \\
CB-C-F0-I40-B & 229.6 & 154.3 & 37.7 \\
CB-C-F0-I40-TB & 238.4 & 162.5 & 38.7 \\
CB-C-F2-I40-T & 247.5 & 170.5 & 38.5 \\
CB-C-F2-I40-B & 254.6 & 176.1 & 39.3 \\
CB-C-F2-I40-TB & 261.1 & 178.2 & 41.5 \\
CB-C-F2-I40-TB-R & 260.3 & 176.2 & 42.1 \\
\hline
\end{tabular}


Table 6. Results comparison of the five-point bending tests

\begin{tabular}{|c|c|c|c|c|c|c|c|c|c|}
\hline Specimens & $\begin{array}{l}\text { Hogging } \\
\text { region yield } \\
\text { loads } \\
(\mathrm{kN})\end{array}$ & $\begin{array}{c}\text { Comparison } \\
\text { to the } \\
\text { reference } \\
\text { beam }\end{array}$ & $\begin{array}{c}\text { Comparison } \\
\text { to the } \\
\text { corroded } \\
\text { beam }\end{array}$ & $\begin{array}{c}\text { Sagging } \\
\text { region yield } \\
\text { loads } \\
(\mathrm{kN})\end{array}$ & $\begin{array}{c}\text { Comparison } \\
\text { to the } \\
\text { reference } \\
\text { beam }\end{array}$ & $\begin{array}{c}\text { Comparison } \\
\text { to the } \\
\text { corroded } \\
\text { beam }\end{array}$ & $\begin{array}{l}P_{u-\exp } \\
(\mathrm{kN})\end{array}$ & $\begin{array}{c}\text { Comparison } \\
\text { to the } \\
\text { reference } \\
\text { beam }\end{array}$ & $\begin{array}{c}\text { Comparison } \\
\text { to the } \\
\text { corroded } \\
\text { beam }\end{array}$ \\
\hline CB-RF & 151.1 & --- & 1.20 & 196.2 & --- & 1.18 & 240.6 & --- & 1.10 \\
\hline CB-C-F0-I0 & 125.8 & 0.83 & --- & 166.3 & 0.85 & --- & 219.1 & 0.91 & ---- \\
\hline CB-C-F0-I40-T & 145.3 & 0.96 & 1.16 & 175.4 & 0.85 & 1.01 & 233.2 & 0.97 & 1.06 \\
\hline CB-C-F0-I40-B & 142.5 & 0.94 & 1.13 & 171.7 & 0.91 & 1.07 & 229.6 & 0.95 & 1.05 \\
\hline CB-C-F0-I40-TB & 168.6 & 1.12 & 1.34 & 193.4 & 1.04 & 1.22 & 238.4 & 0.99 & 1.09 \\
\hline CB-C-F2-I40-T & 230.8 & 1.53 & 1.83 & 216.8 & 1.10 & 1.30 & 247.5 & 1.03 & 1.13 \\
\hline CB-C-F2-I40-B & 200.4 & 1.33 & 1.59 & 239.5 & 1.22 & 1.44 & 254.6 & 1.06 & 1.16 \\
\hline CB-C-F2-I40-TB & 208.0 & 1.38 & 1.65 & 230.2 & 1.17 & 1.38 & 261.1 & 1.09 & 1.19 \\
\hline CB-C-F2-I40-TB-R & 221.1 & 1.46 & 1.76 & 243.4 & 1.24 & 1.46 & 260.3 & 1.09 & 1.19 \\
\hline
\end{tabular}


Table 7. Hogging moments, sagging moments and ductility at failure of the test specimens

\begin{tabular}{lccccccc}
\hline Specimens & $M_{\text {uh-exp }}$ & $\begin{array}{c}\text { Comparison } \\
\text { to the } \\
\text { reference } \\
\text { beam }\end{array}$ & $\begin{array}{c}\text { Comparison } \\
\text { to the } \\
\text { corroded } \\
\text { beam }\end{array}$ & $\begin{array}{c}\text { Comparison } \\
\text { to the } \\
\text { reference } \\
\text { beam }\end{array}$ & $\begin{array}{c}\text { Comparison } \\
\text { to the } \\
\text { corroded } \\
\text { beam }\end{array}$ & $\mu_{\Delta}$ \\
\hline CB-RF & 24.48 & --- & 1.18 & 20.85 & --- & 1.06 & 6.05 \\
CB-C-F0-I0 & 20.76 & 0.85 & --- & 19.75 & 0.95 & --- & 5.33 \\
CB-C-F0-I40-T & 22.33 & 0.91 & 1.08 & 20.90 & 1.00 & 1.06 & 3.81 \\
CB-C-F0-I40-B & 21.73 & 0.89 & 1.05 & 20.71 & 0.99 & 1.05 & 3.92 \\
CB-C-F0-I40-TB & 23.82 & 0.97 & 1.15 & 20.87 & 1.00 & 1.06 & 4.50 \\
CB-C-F2-I40-T & 25.71 & 1.05 & 1.24 & 21.18 & 1.02 & 1.07 & 3.31 \\
CB-C-F2-I40-B & 26.84 & 1.10 & 1.29 & 21.59 & 1.04 & 1.09 & 1.66 \\
CB-C-F2-I40-TB & 26.21 & 1.07 & 1.26 & 22.80 & 1.09 & 1.15 & 3.03 \\
CB-C-F2-I40-TB-R & 25.33 & 1.03 & 1.22 & 23.13 & 1.11 & 1.17 & 1.26 \\
\hline
\end{tabular}

Table 8. Strains of the steel reinforcements at failure

\begin{tabular}{lcc}
\hline Specimens & $\mathcal{E}_{\text {steel, } h}$ & $\mathcal{E}_{\text {steel,s }}$ \\
\hline CB-RF & $>0.00259$ & $>0.00253$ \\
CB-C-F0-I0 & $>0.00357$ & $>0.00232$ \\
CB-C-F0-I40-T & $>0.00282$ & $>0.00215$ \\
CB-C-F0-I40-B & $>0.00202$ & $>0.00276$ \\
CB-C-F0-I40-TB & - & - \\
CB-C-F2-I40-T & 0.00230 & $>0.00192$ \\
CB-C-F2-I40-B & 0.00406 & $>0.00227$ \\
CB-C-F2-I40-TB & - & 0.00277 \\
CB-C-F2-I40-TB-R & 0.00175 & 0.00185 \\
\hline
\end{tabular}


Table 9. Strains of the CF meshes at failure

\begin{tabular}{lcc}
\hline Specimens & $\mathcal{E}_{f r p, h}$ & $\mathcal{E}_{f r p, s}$ \\
\hline CB-C-F2-I40-T & 0.00211 & - \\
CB-C-F2-I40-B & - & 0.00239 \\
CB-C-F2-I40-TB & - & 0.00320 \\
CB-C-F2-I40-TB-R & 0.00194 & 0.00220 \\
\hline
\end{tabular}

Table 10. Predicted capacities of the hogging and sagging regions.

\begin{tabular}{lcccccc}
\hline Specimens & $\begin{array}{c}M_{u h-549} \\
(\mathrm{kNm})\end{array}$ & $\begin{array}{c}M_{u s-549} \\
(\mathrm{kNm})\end{array}$ & $\begin{array}{c}M_{u h-440} \\
(\mathrm{kNm})\end{array}$ & $\begin{array}{c}M_{u s-440} \\
(\mathrm{kNm})\end{array}$ & $\begin{array}{c}M_{u h-A s h} \\
(\mathrm{kNm})\end{array}$ & $\begin{array}{c}M_{u s-A s h} \\
(\mathrm{kNm})\end{array}$ \\
\hline CB-RF & 19.87 & 19.87 & 19.87 & 19.87 & 19.87 & 19.87 \\
CB-C-F0-I0 & 17.16 & 17.16 & 17.16 & 17.16 & 17.16 & 17.16 \\
CB-C-F0-I40-T & 18.66 & 17.71 & 18.66 & 17.71 & 18.66 & 17.71 \\
CB-C-F0-I40-B & 17.90 & 18.79 & 17.90 & 18.79 & 17.90 & 18.79 \\
CB-C-F0-I40-TB & 19.14 & 19.14 & 19.14 & 19.14 & 19.14 & 19.14 \\
CB-C-F2-I40-T & 28.84 & 18.15 & 32.61 & 18.15 & 37.69 & 18.15 \\
CB-C-F2-I40-B & 18.60 & 28.90 & 18.60 & 32.67 & 18.60 & 37.75 \\
CB-C-F2-I40-TB & 29.08 & 29.08 & 32.85 & 32.85 & 37.93 & 37.93 \\
CB-C-F2-I40-TB-R & 29.23 & 29.23 & 33.01 & 33.01 & 38.07 & 38.07 \\
\hline
\end{tabular}


Table 11. Comparison of the experimental bending moments and cross-section theoretical moment capacities

\begin{tabular}{|c|c|c|c|c|c|c|}
\hline Specimens & $\frac{M_{u h-\exp }}{M_{u h-549}}$ & $\frac{M_{u s-\exp }}{M_{u s-549}}$ & $\frac{M_{u h-\exp }}{M_{u h-440}}$ & $\frac{M_{u s-\exp }}{M_{u s-440}}$ & $\frac{M_{u h-\exp }}{M_{u h-A s h}}$ & $\frac{M_{u s-\exp }}{M_{u s-A s h}}$ \\
\hline CB-RF & 1.23 & 1.05 & 1.23 & 1.05 & 1.23 & 1.05 \\
\hline CB-C-F0-I0 & 1.21 & 1.15 & 1.21 & 1.15 & 1.21 & 1.15 \\
\hline CB-C-F0-I40-T & 1.20 & 1.18 & 1.20 & 1.18 & 1.20 & 1.18 \\
\hline CB-C-F0-I40-B & 1.21 & 1.10 & 1.21 & 1.10 & 1.21 & 1.10 \\
\hline CB-C-F0-I40-TB & 1.24 & 1.09 & 1.24 & 1.09 & 1.24 & 1.09 \\
\hline CB-C-F2-I40-T & $0.89^{*}$ & 1.17 & $0.79 *$ & 1.17 & $0.68^{*}$ & 1.17 \\
\hline CB-C-F2-I40-B & 1.44 & $0.75^{*}$ & 1.44 & $0.66^{*}$ & 1.44 & $0.57^{*}$ \\
\hline CB-C-F2-I40-TB & $0.90^{*}$ & $0.78^{*}$ & $0.80^{*}$ & $0.69^{*}$ & $0.69^{*}$ & $0.60 *$ \\
\hline CB-C-F2-I40-TB-R & $0.87^{*}$ & $0.79 *$ & $0.77 *$ & $0.70 *$ & $0.67 *$ & $0.61 *$ \\
\hline
\end{tabular}

Note: * means strengthened sections

Table 12. Comparison between the predicted loading capacities using elastic theory and the experimental results

\begin{tabular}{|c|c|c|c|c|c|c|}
\hline Specimens & $\frac{P_{u-\exp }}{P_{549}^{e l}}$ & $\frac{P_{u-\exp }}{P_{549}^{p l}}$ & $\frac{P_{u-\exp }}{P_{440}^{e l}}$ & $\frac{P_{u-\exp }}{P_{440}^{p l}}$ & $\frac{P_{u-\exp }}{P_{A s h}^{e l}}$ & $\frac{P_{u-\exp }}{P_{A s h}^{p l}}$ \\
\hline CB-RF & 1.25 & 1.11 & 1.25 & 1.11 & 1.25 & 1.11 \\
\hline CB-C-F0-I0 & 1.32 & 1.17 & 1.32 & 1.17 & 1.32 & 1.17 \\
\hline CB-C-F0-I40-T & 1.29 & 1.19 & 1.29 & 1.19 & 1.29 & 1.19 \\
\hline CB-C-F0-I40-B & 1.32 & 1.14 & 1.32 & 1.14 & 1.32 & 1.14 \\
\hline CB-C-F0-I40-TB & 1.28 & 1.14 & 1.28 & 1.14 & 1.28 & 1.14 \\
\hline CB-C-F2-I40-T & 1.17 & 1.04 & 1.17 & 0.99 & 1.17 & 0.92 \\
\hline CB-C-F2-I40-B & 1.41 & 0.92 & 1.41 & 0.83 & 1.41 & 0.74 \\
\hline CB-C-F2-I40-TB & 0.93 & 0.82 & 0.82 & 0.73 & 0.71 & 0.63 \\
\hline CB-C-F2-I40-TB-R & 0.92 & 0.82 & 0.81 & 0.72 & 0.71 & 0.63 \\
\hline
\end{tabular}




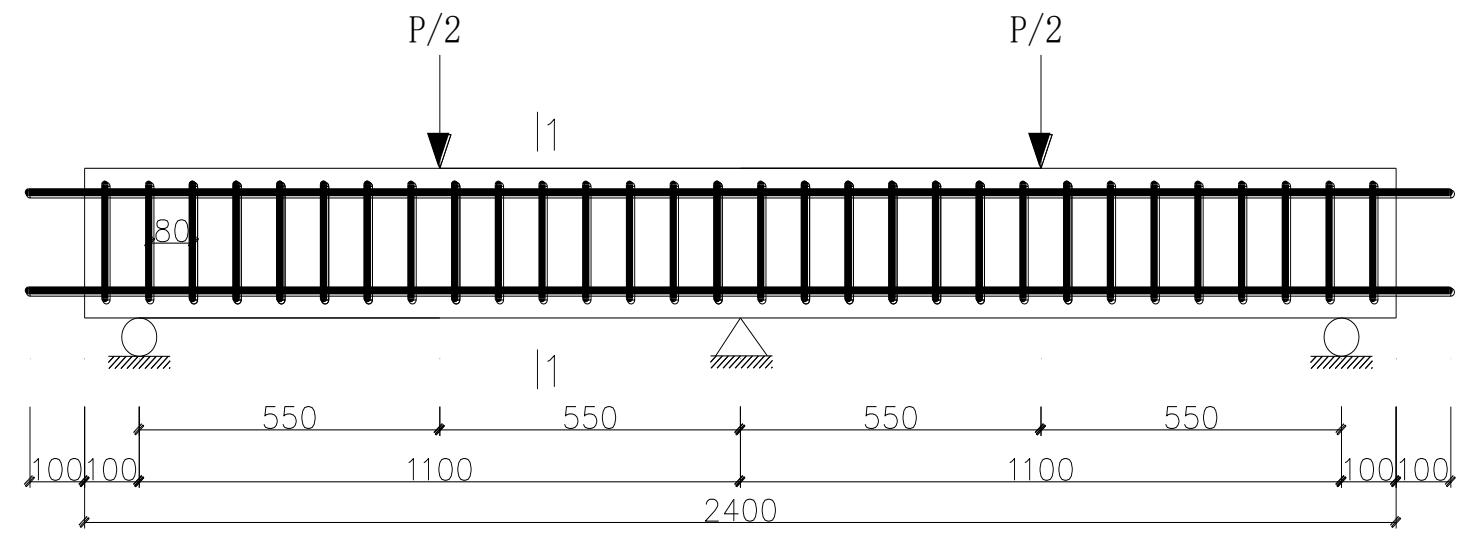

(a) Side view

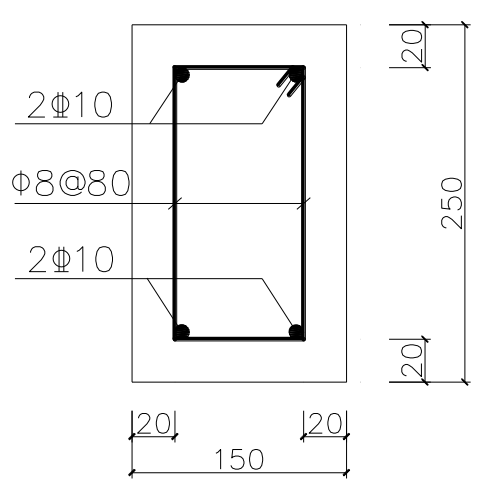

(b) Cross-section view

Fig. 1. Dimensions and configuration of the reinforcements of the test specimens (all dimensions in $\mathrm{mm}$ )

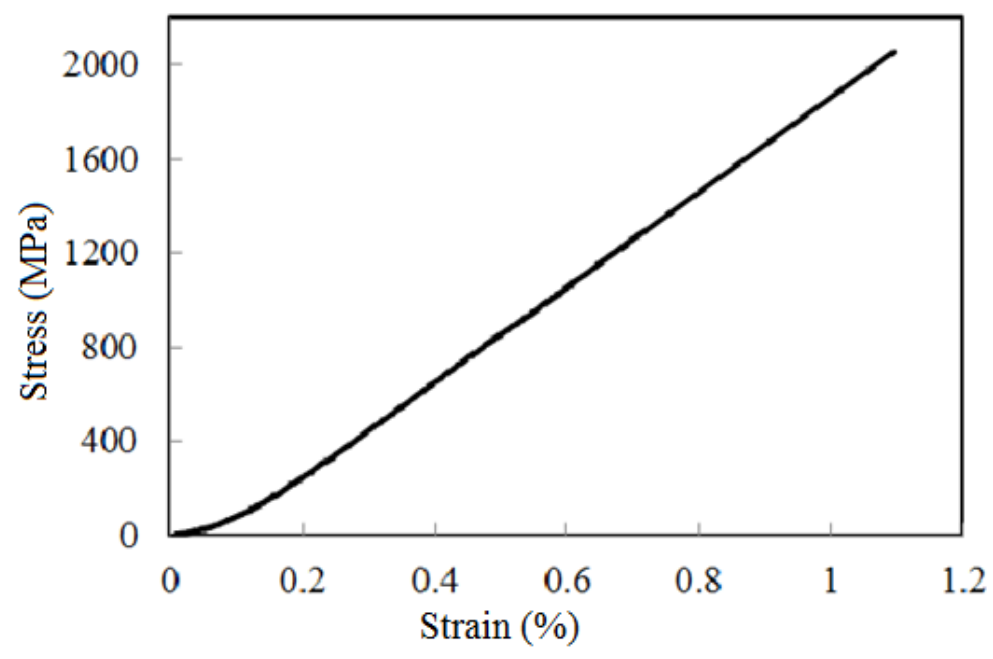

Fig. 2. Stress-strain curve of a CFRP tow 


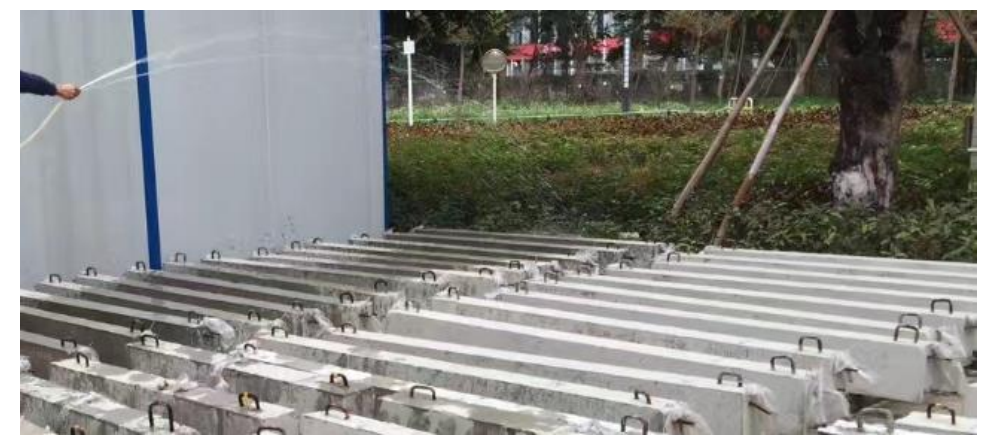

Fig. 3. Accelerated corrosion of specimens using wet-dry cycles

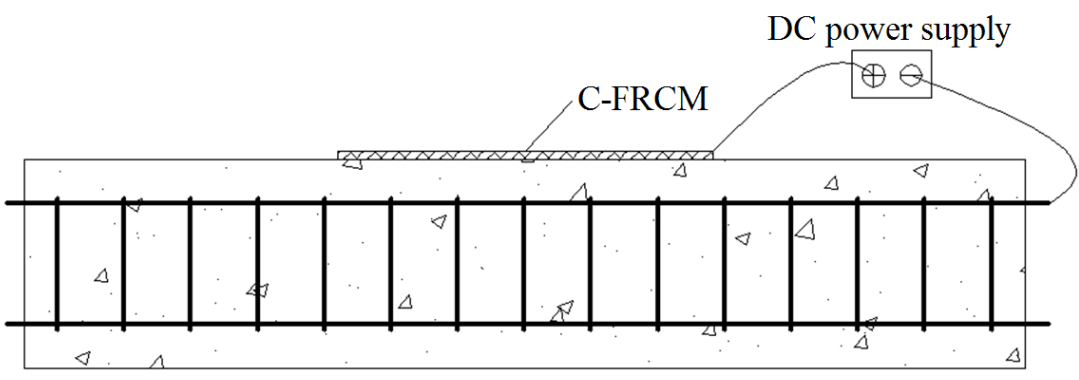

(a) Applied to the hogging moment region

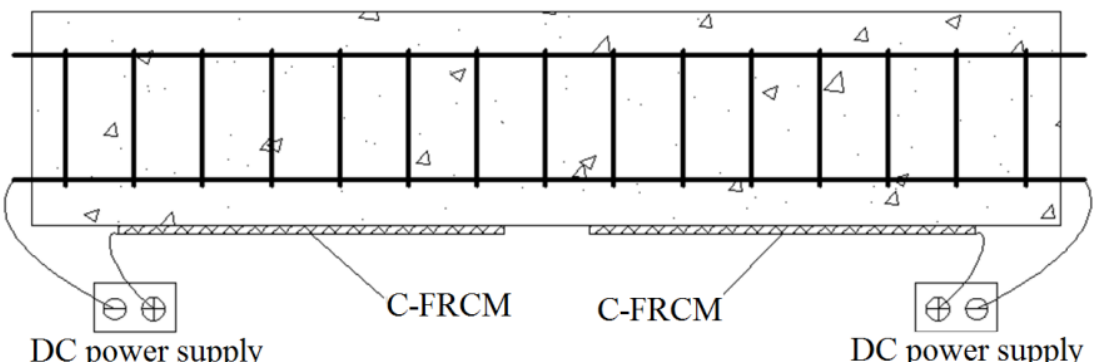

(b) Applied to the sagging moment region

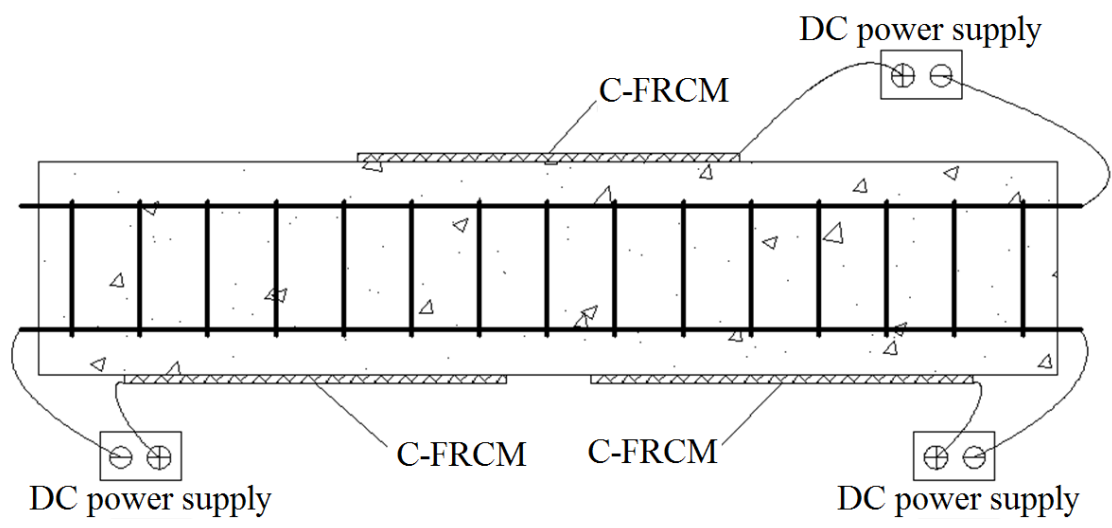

(c) Applied to both the hogging and the sagging moment regions

Fig. 4. Schematic drawing of the strengthening and cathodic protection on different regions of the specimens 


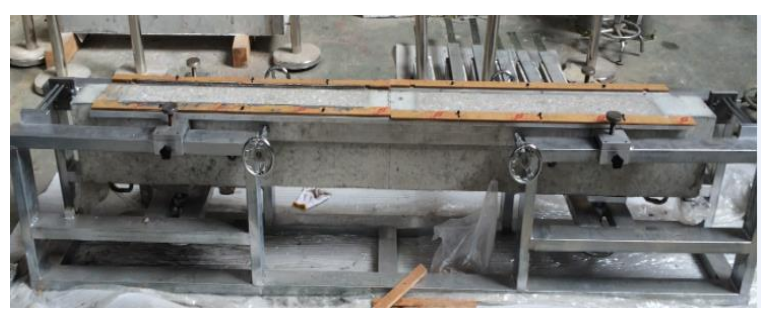

(a) Sand blasting the surface

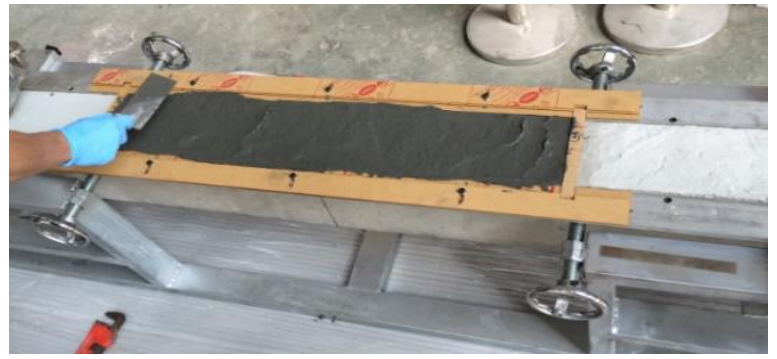

(b) First layer of cementitious matrix

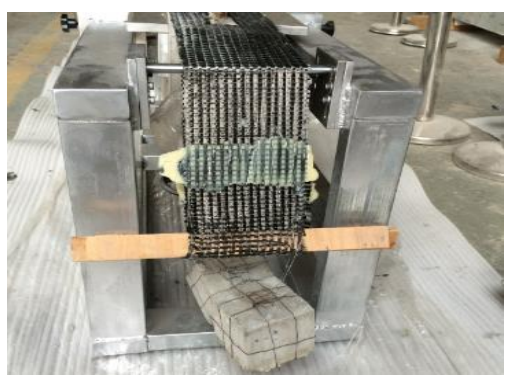

(c) Straightening the CF meshes

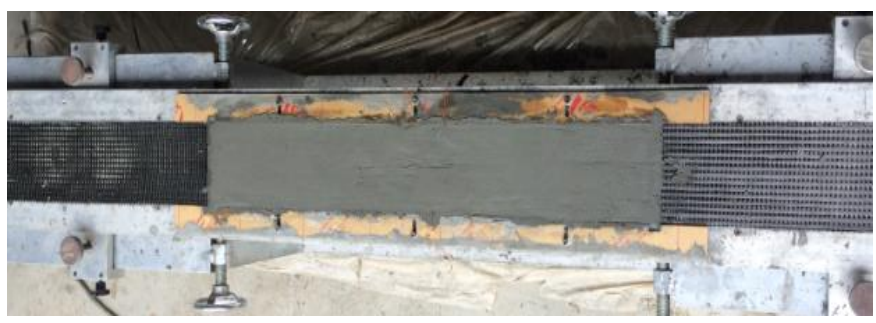

(d) Top surface of the cementitious matrix layer

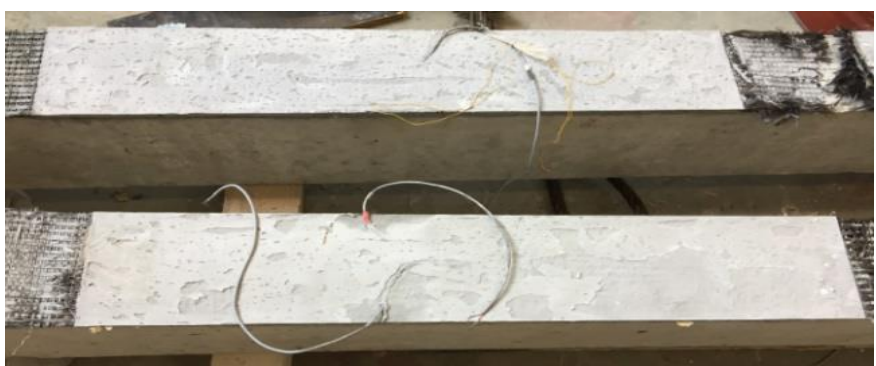

(e) Finished surface after 28 days of curing

Fig. 5. C-FRCM retrofitting process 


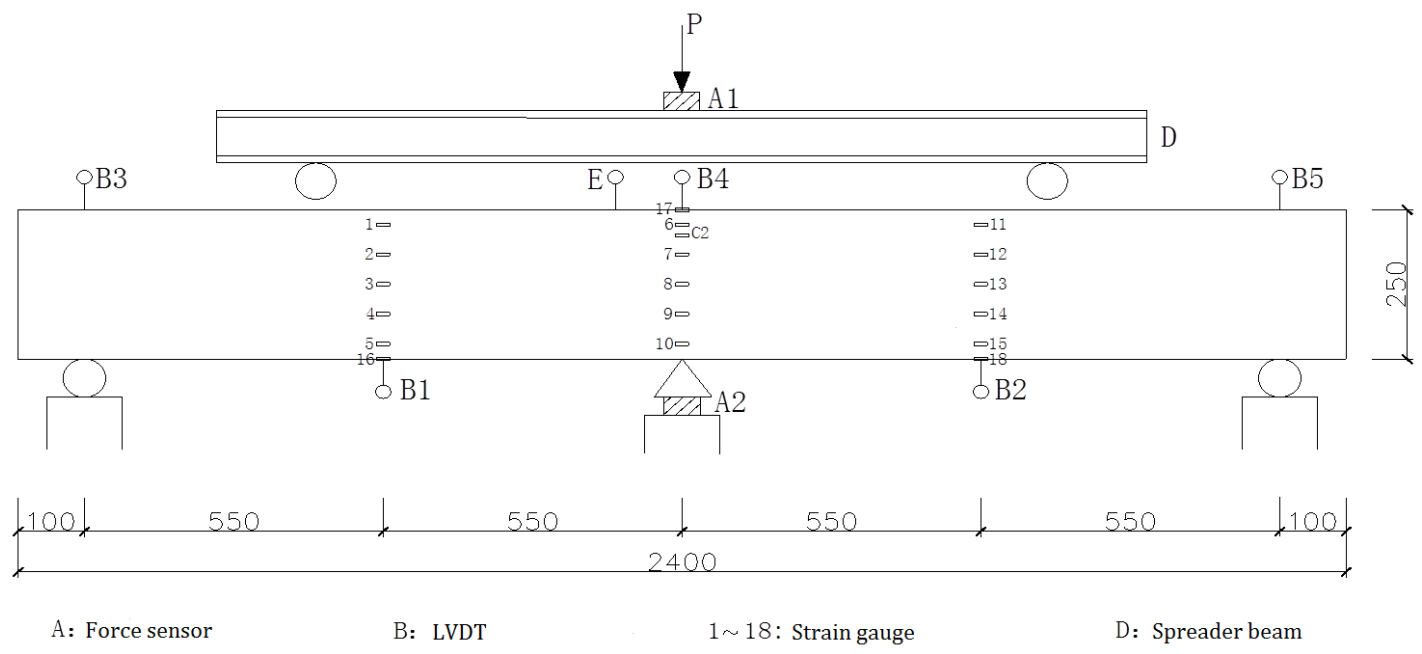

(a) Schematic drawing

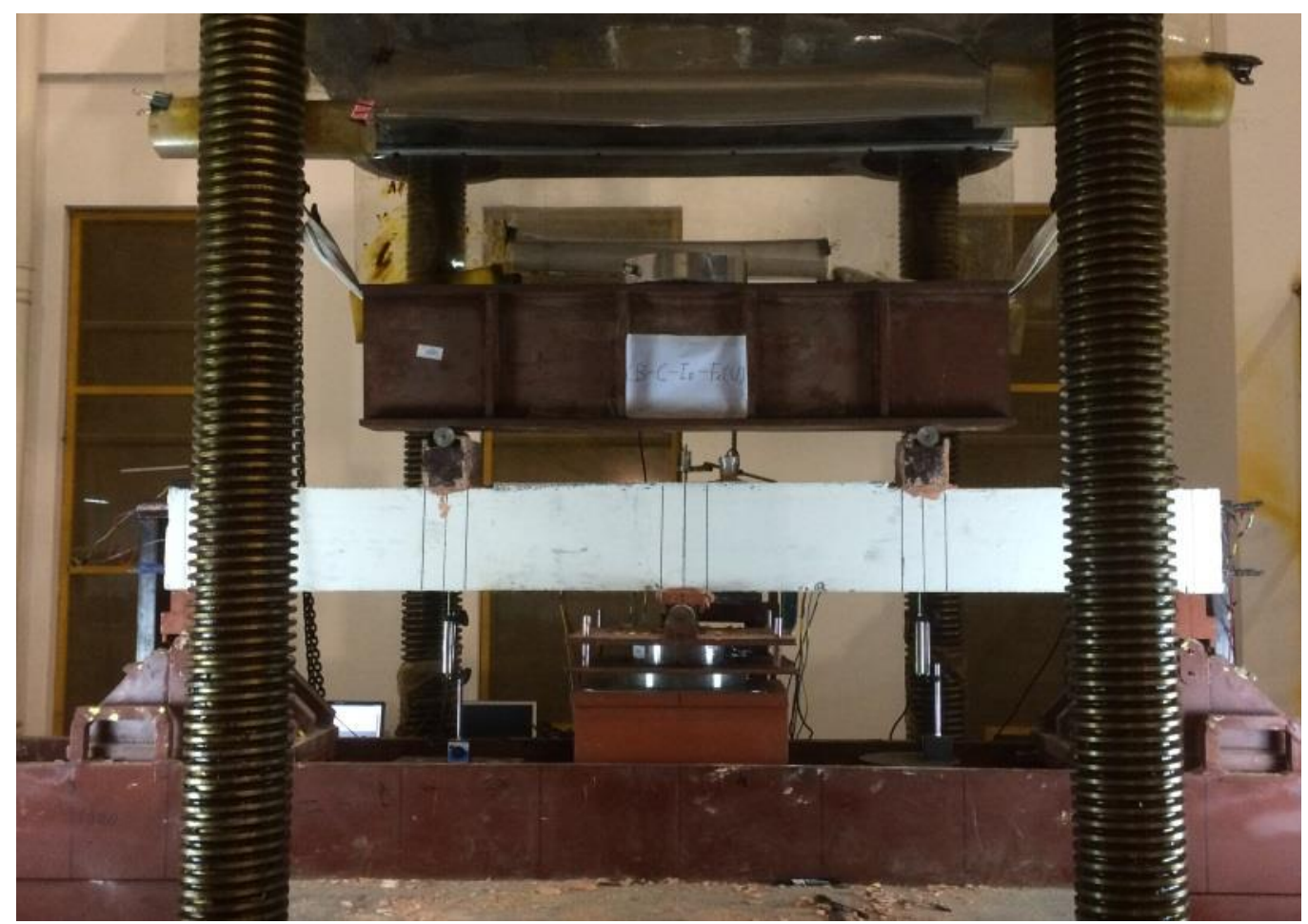

(b) Test configuration

Fig. 6. Setup of the five-point bending tests 


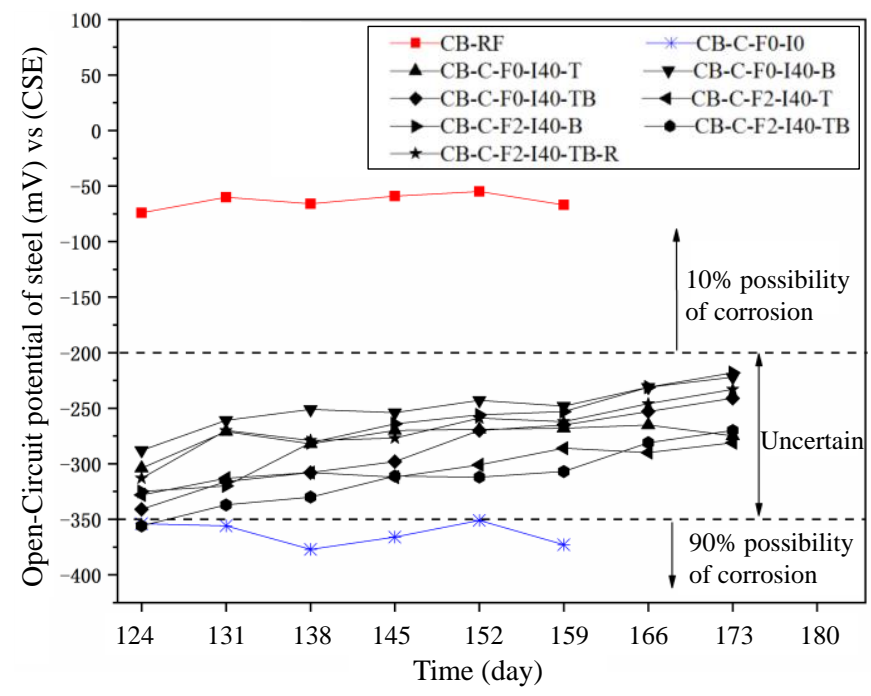

(a) Open-circuit potentials

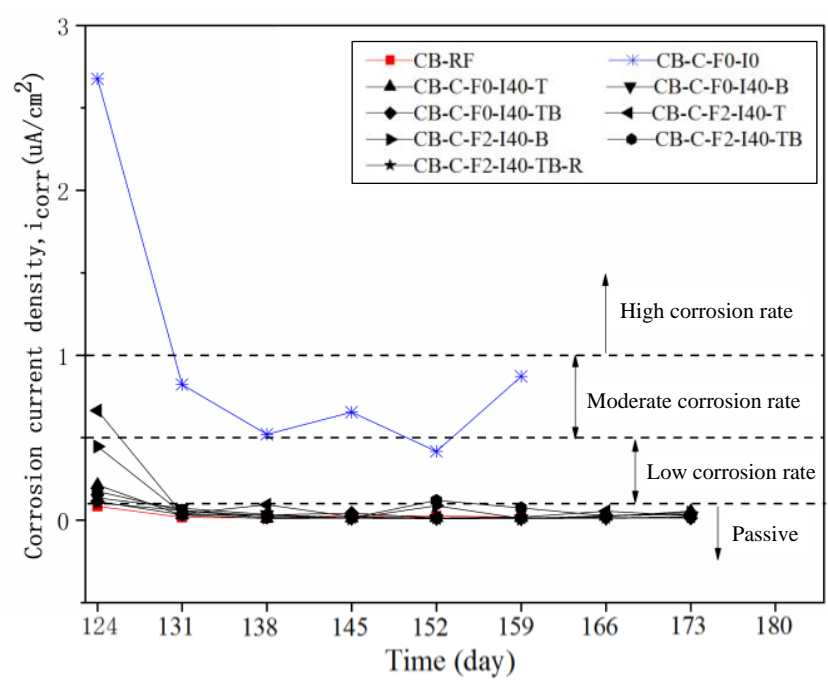

(b) Corrosion current densities

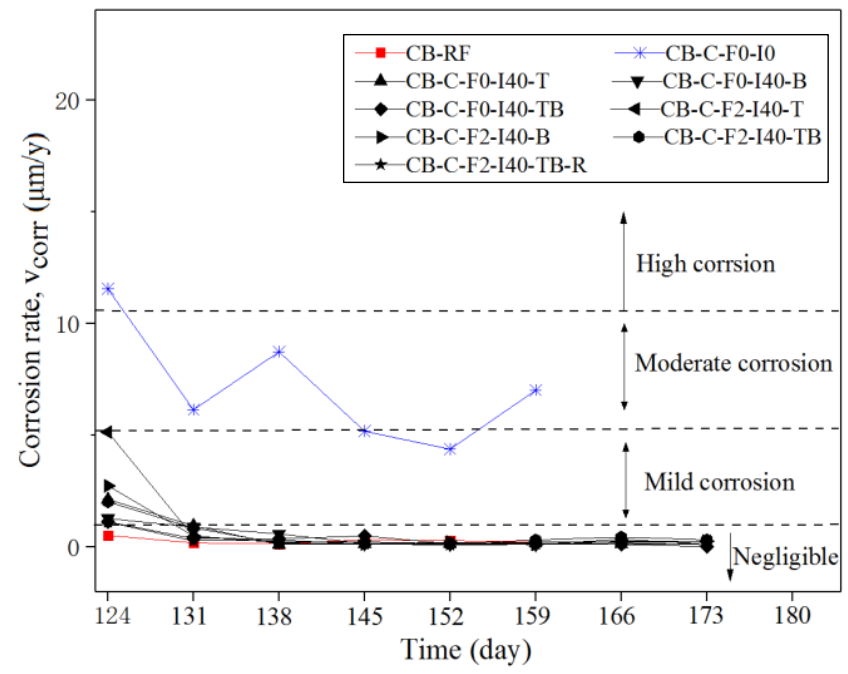

(c) Corrosion rates

Fig. 7 Electrochemical measurement results of the steel reinforcements 


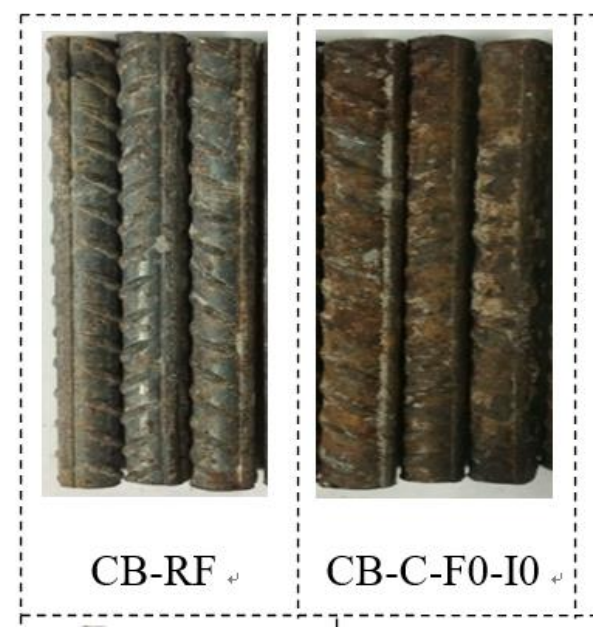

Fig. 8. Observation of the reinforcements from the tested beams

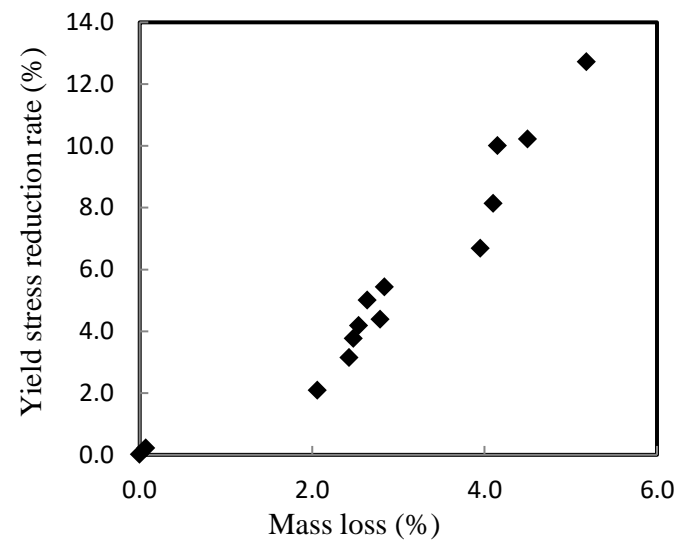

(a) Yield stress

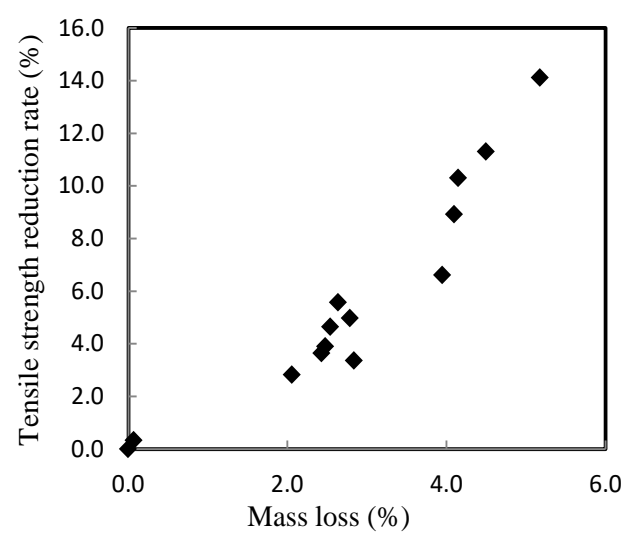

(b) Ultimate stress

Fig. 9. Relation between the strength reduction in the reinforcements and their mass losses due to corrosion 


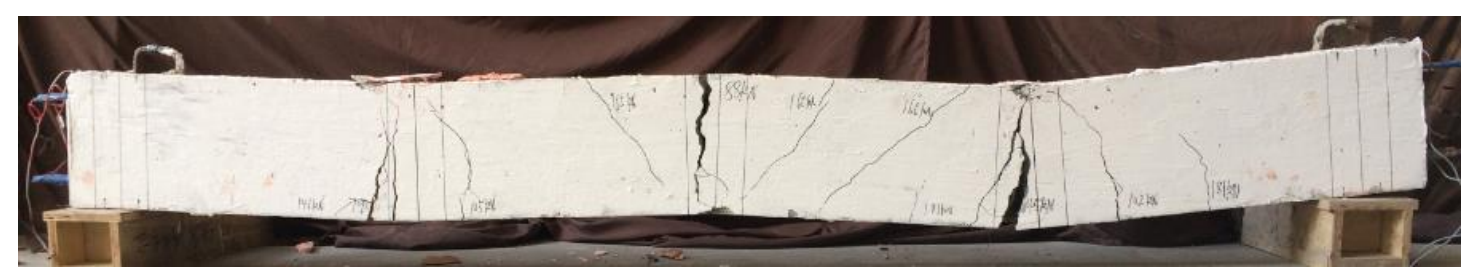

(a) Unstrengthened beams (CB-RF)

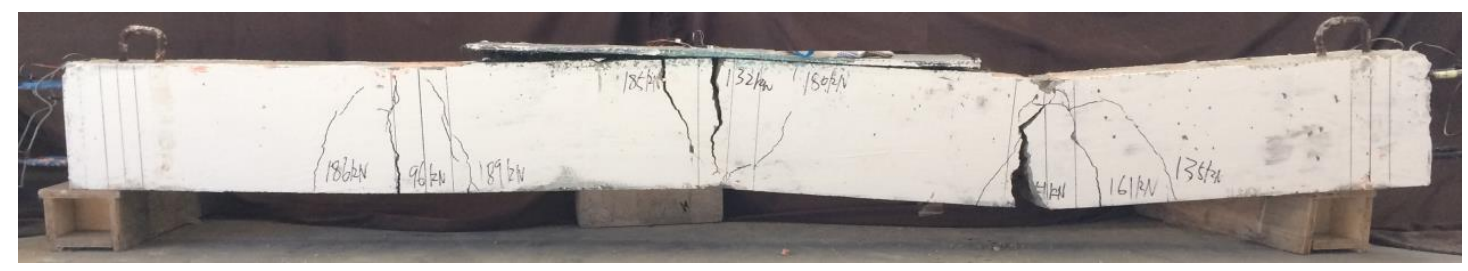

(b) Beams strengthened on the hogging moment region (CB-C-F2-I40-T)

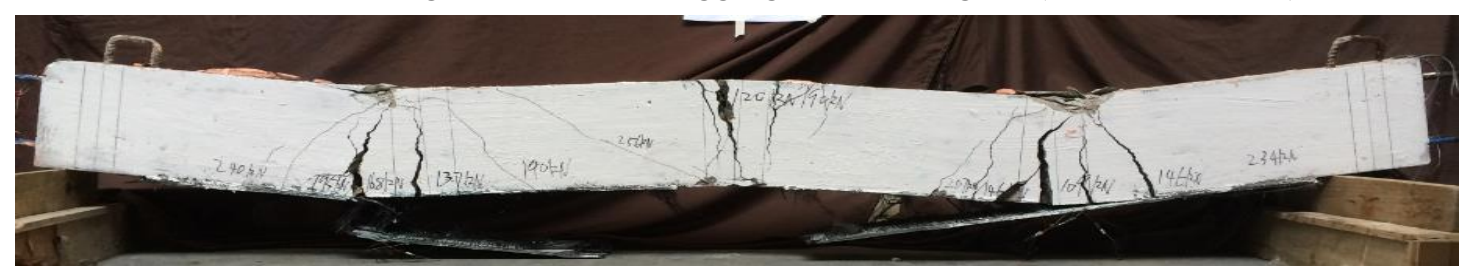

(c) Beams strengthened on the sagging moment regions (CB-C-F2-I40-B)

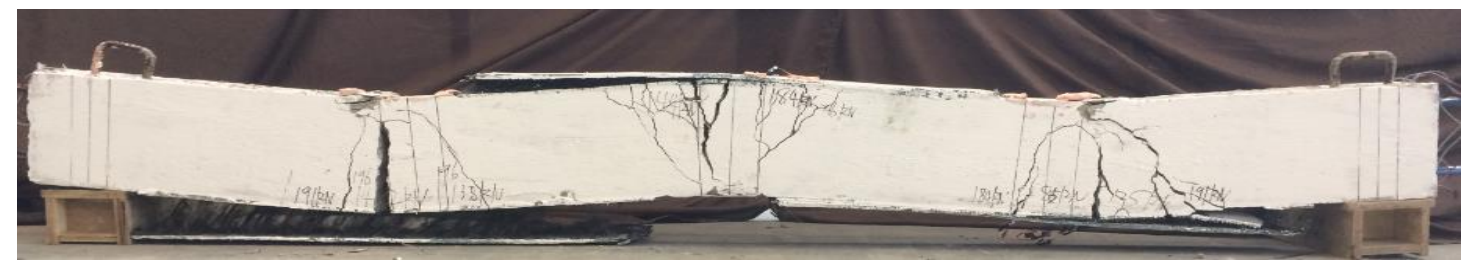

(d) Beams strengthened on both the hogging and the sagging moment regions

(CB-C-F2-I40-TB)

Fig. 10. Failure modes of the tested beams

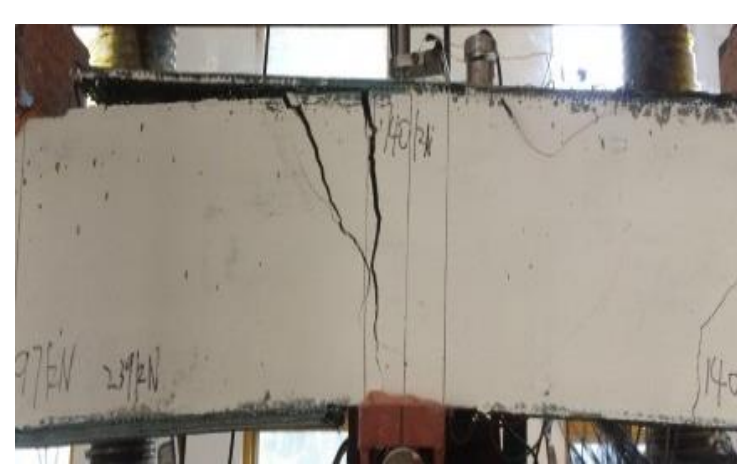

(a) Hogging moment region

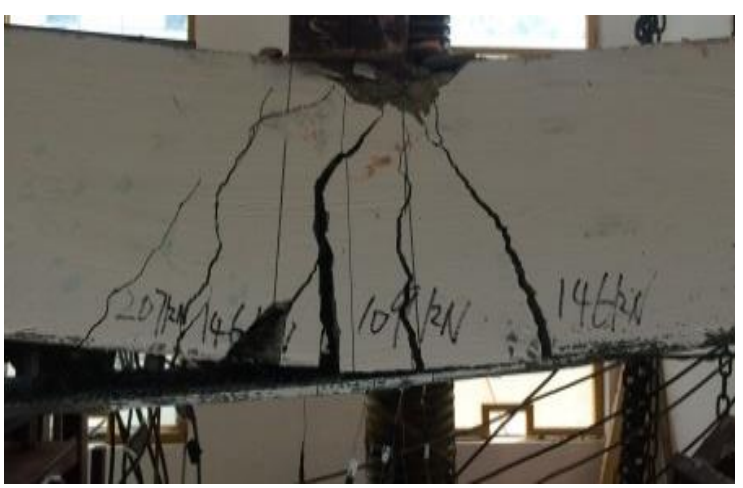

(b) Sagging moment region

Fig. 11 Debonding failure of the C-FRCM 


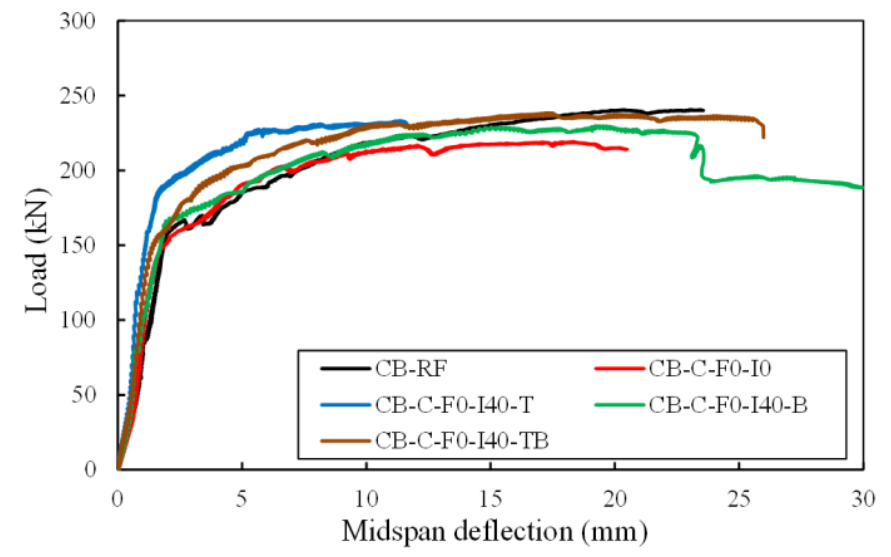

(a) Unstrengthened specimens

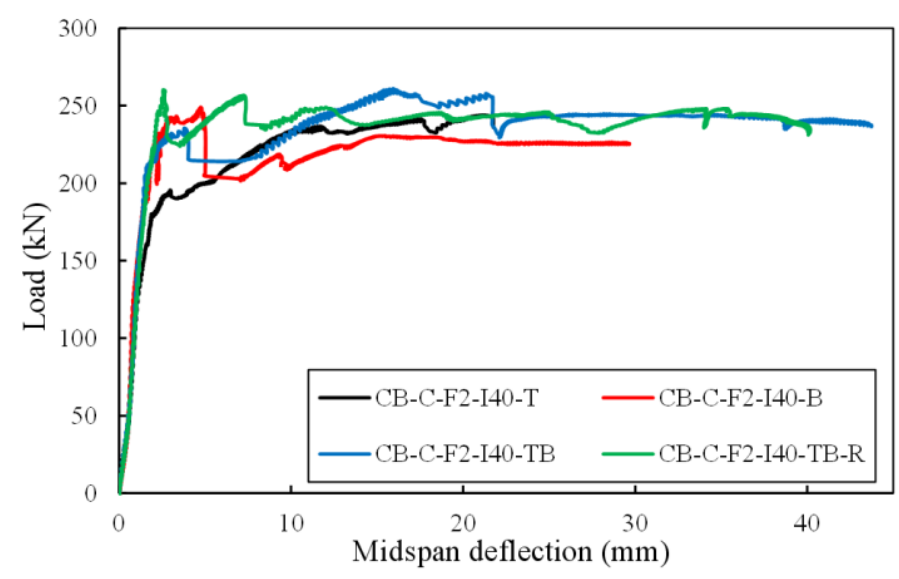

(b) Strengthened specimens

Fig. 12. Load-deflection curves of the tested beams

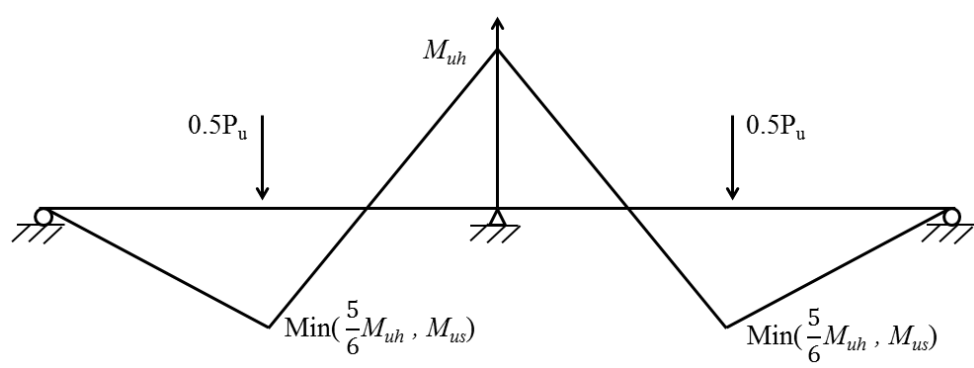

(a) Global elastic approach

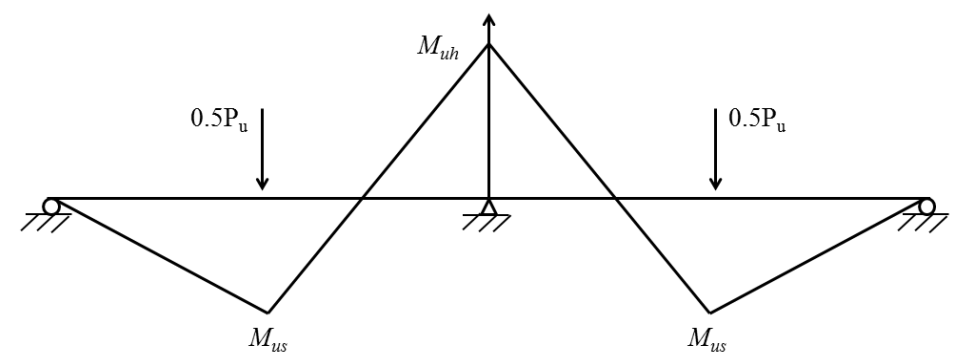

(b) Global plastic prediction

Fig. 13 Theoretical bending moment diagram of beams subjected to five-point bending 